\title{
ETNOGUBERNAMENTALIDAD. LA FORMACIÓN DEL CAMPO DE LA SALUD INTERCULTURAL EN CHILE
}

\author{
ETHNO-GOVERNMENTALITY. THE MAKING OF THE INTERCULTURAL \\ HEALTH FIELD IN CHILE
}

\author{
Guillaume Bruno Boccara ${ }^{1}$
}

En 2001 se empezó a implementar en Chile el Programa de Desarrollo Integral de Comunidades Indígenas llamado Orígenes, que se presenta como un dispositivo de intervención respetuoso de las diferencias culturales cuyo propósito es "desarrollar una política de cooperación entre los Pueblos Indígenas y el Estado" y "contribuir al desarrollo" de los pueblos nativos del sector rural. En el presente ensayo me propongo dar cuenta de la naturaleza de este neoindigenismo tanto a través del análisis de la producción de conocimientos por las agencias de Estado a nivel macro como a través del estudio microsociológico de las relaciones de poder y del tipo de saber generado por los agentes estatales y paraestatales a cargo de la ejecución de ese programa. Centrando mi presentación en uno de los componentes de Orígenes, muestro que la llamada Salud Intercultural representa una nueva ingeniería social que toma sentido dentro de un nuevo diagrama de saber/poder que llamo etnogubernamentalidad. Constituye una nueva gestión de la alteridad y un recorte del cuerpo social en clave étnica. Veremos por lo tanto que este nuevo objeto de la salud pública debe ser aprehendido en su dimensión política. Concomitante a la emergencia de este subcampo de la Salud Intercultural, surgen nuevas disputas de significaciones y clasificaciones en torno a los mismísimos términos de Salud y Cultura. Se trata por lo tanto de dar cuenta de la dimensión política de la salud, vale decir, de la constitución de los cuerpos indígenas como sujetos y objetos de gobierno.

Palabras claves: salud intercultural, subjetificación, etnogubernamentalidad, pueblo mapuche, neoindigenismo.

In 2001, the Chilean State began to implement an ethnodevelopment program directed at the indigenous communities of its national territory. Called Origins, this unprecedented political initiative aims at establishing a new deal between the State and rural ethnic groups and claims to be based on the respect of cultural difference. This paper offers an interpretation of the nature of this new kind of indigenism through the analysis of the state-produced knowledge on indigenous peoples, on the one hand, and by focusing on the new power relations and subjectifying effects created by state agents in specific localities, on the other. I shall show, using a discourse and socio-ethnographic analysis of its intercultural health component, that Orígenes represents a powerful device of subject-making and ethnification. I shall focus on the classifying, spatializing and hegemonizing effects produced by what I call, taking up on Foucault's approach on biopower and drawing on recent ethnographies of the neoliberal state, the multicultural governmentality. I shall finally contend that, closely intertwined with this new social engineering, indigenous counterhegemonic discourses, knowledges and practices are starting to emerge that fully contribute to the shaping of this new intercultural battle field. Therefore, this paper deals with the political dimensions of health, that is with the constitution of the indigenous body as subject and object of government.

Key words: Intercultural health, subject-making, ethnogovernmentality, Mapuche people, neoindigenism.

Hay una gran contaminación en nuestras comunidades y donde nuevamente el mismo sistema occidental, con todos sus mecanismos y con todas sus máquinas que tiene, siguen reprimiendo la salud misma. Victor Caniullán, Machi (Shaman), Comuna de Carahue. Tercer Encuentro Nacional de Salud y Pueblos Indígenas, Villarrica, 1999.
La interculturalidad es un tema que le interesa más bien al Estado de cómo poder hacer que los pueblos originarios se comporten como el Estado quiere. Jaime Ibacache, médico, Villarrica 1999. Ex director de la Unidad de Salud con Población Mapuche. Servicio de Salud Araucanía Sur.

1 Universidad Católica del Norte, IIAM, Calle Gustavo Le Paige 380, San Pedro de Atacama, II Región, Chile. gboccara@ucn.cl. GETIME (Grupo de Estudio sobre Territorialidades Indígenas y Multiculturalismo de Estado del IIAM). 
El Estado no es nada más que el efecto móvil de un régimen de gubernamentalidad múltiple. No se trata de descubrir el secreto del Estado. Se trata de inquirir sobre el problema del Estado a partir de las prácticas de gubernamentalidad. Michel Foucault, Cours au Collège de France, 1979.

En 2001 se empezó a implementar en Chile la primera fase del Programa de Desarrollo Integral de Comunidades Indígenas financiado en parte a través de un préstamo del Banco Interamericano de Desarrollo ${ }^{1}$. Este proyecto de US\$ 133 millones representa sin lugar a dudas un hito en la historia de las relaciones del Estado chileno con los pueblos indígenas que habitan el territorio nacional. Es llamado Orígenes en referencia a las poblaciones originarias focalizadas; el programa se presenta como un dispositivo de intervención respetuoso de las diferencias culturales que tiene como meta permitir desarrollar una política de cooperación entre los pueblos indígenas y el Estado, haciendo más pertinentes las respuestas de éste, con el propósito de contribuir al desarrollo y mejoramiento de la calidad de vida de los pueblos aymara, atacameño y mapuche del sector rural (Orígenes 2004).

Además de acciones en desarrollo productivo, educación y fortalecimiento institucional, Orígenes consta de un componente de salud que contempla el diseño e implementación de "un modelo de salud intercultural" a través del "fortalecimiento de la medicina indígena" y la "sensibilización de los funcionarios del sistema de salud" a la tématica indígena para "mejorar el trato y la pertinencia cultural en la atención a la población indígena".

En el presente ensayo nos proponemos abordar, a través del estudio del subcomponente capacitación del componente salud, la manera como este programa se ha ido implementando y las prácticas y los principios políticos, sociales y culturales que lo sustentan. El objetivo general de este trabajo es dar cuenta de la naturaleza de este neoindigenismo de Estado a través del estudio acotado de la política de salud intercultural y de la concomitante reconfiguración del espacio terapéutico. Para ello, no sólo analizaremos los planteamientos oficiales de las autoridades políticas naciona- les con respecto de la implementación de "un modelo de salud con pertinencia cultural", sino que estudiaremos también, desde una aproximación microsociológica y etnográfica, la producción de nuevas relaciones de poder y de un nuevo tipo de saber en lo que llamaremos el subcampo de la Salud Intercultural. Es así como abordaremos el problema de la construcción de la etnicidad y de la llamada "sociedad pluriétnica y multicultural" a partir de lo que los distintos agentes sociales (de Estado o no) expresan y hacen en un segmento bien particular de la esfera pública, a saber: el nuevo espacio social definido como el de la Salud Intercultural.

En este artículo definimos a la salud intercultural como subcampo, en el sentido bourdieusiano del concepto ${ }^{2}$, pues se encuentra englobado dentro de un campo burocrático mayor, el de la salud pública, tanto desde el punto de vista institucional como administrativo y conceptual. Desde esta perspectiva, planteamos que la Salud Intercultural representa una nueva ingeniería social que se inscribe dentro de un nuevo diagrama de saber/poder o de una gubernamentalidad de un nuevo tipo ${ }^{3}$ que tiende a producir nuevos sujetos étnicos colectivos e individuales a través de una doble dinámica de etnicización y de responsabilización. A través de la puesta en marcha de programas de salud intercultural, son las relaciones entre cuerpo social y cuerpo individual, esfera pública y esfera privada, individuo y población y Estado y ciudadano que se encuentran repensadas y modificadas (Fassin y Memmi 2004:11). Por lo tanto, lo que pretendemos demostrar es que lo que está en juego en la delimitación de este nuevo segmento de la esfera de intervención del Estado es mucho más que el "respeto a la alteridad" o "el reconocimiento a la diversidad cultural del país" como afirman los nuevos etnoburócratas del neoindigenismo de Estado. Desde esta perspectiva, el campo social y semántico de la interculturalidad, entendido como juego concreto entre los agentes (Fassin 2000) y no como entidad abstracta, remite más bien a una nueva gestión de la diversidad, a la emergencia de nuevos modos de legitimación de las prácticas y de los agentes terapéuticos llamados tradicionales, a una redefinición del cuerpo individual y colectivo indígena, así como también, a un nivel más global, a un recorte del cuerpo social en clave étnica. Por otra parte, este nuevo es- 
pacio de la interculturalidad es, como cualquier otro espacio social, un espacio "contestado" y tensionado. Es así como concomitante a la emergencia de este subcampo de la salud intercultural, advertimos el surgimiento de nuevas disputas de significaciones y clasificaciones en torno a los mismísimos términos de Salud y Cultura. De hecho, los agentes sociales indígenas tienden a desarrollar, dentro de este nuevo campo y en función de las posiciones que ocupan, estrategias contrahegemónicas que contribuyen a la configuración del nuevo espacio de la interculturalidad. Parafraseando al antropólogo Didier Fassin (2000), diríamos que se trata de aprehender la construcción política de la salud intercultural, vale decir, de dar cuenta de los mecanismos a través de los cuales se construye la relación entre cuerpo social y cuerpo individual y se definen las configuraciones contemporáneas del espacio terapéutico articulando análisis macrosocial y microsocial. En fin, se trata de repolitizar el campo de la salud intercultural en particular y de la salud pública en general pues tienen que ver fundamentalmente con el gobierno de los cuerpos.

El estudio acotado de la emergencia de la llamada interculturalidad en salud nos ofrecerá la oportunidad de desarrollar una reflexión más amplia tanto sobre el rol del Estado en la producción de la etnicidad como sobre las formas locales y diarias de producción del Estado neoliberal diferencialista ${ }^{4}$ vía el análisis de los actos y de las representaciones de los agentes estatales y paraestatales en el contexto de emergencia de nuevas fronteras del capitalismo global (Ong 2002).

Vayamos ahora a la presentación de la estructura de este ensayo. En una primera parte, abordamos la manera como el campo de la salud intercultural es delimitado y definido en la documentación producida por Orígenes y su coejecutor, el Ministerio de Salud (MINSAL). Evocamos brevemente las críticas más comunes que se han hecho últimamente a la noción de salud intercultural tal como se encuentra definida por el Estado chileno desde sus propios valores e intereses.

En una segunda parte, y con el objetivo de dar cuenta del modus operandi del Estado a nivel microsociológico y de aprehender la fábrica del Estado multicultural en la multiplicidad de sus operaciones discretas, en sus procedimientos, representaciones y ritualizaciones, nos detendremos en el análisis de un taller de capacitación di- rigido a funcionarios de la salud que tuviera lugar en 2003 en la ciudad de Carahue (Novena Región), zona de alta densidad poblacional mapuche. Examinaremos la manera como la Consultora (agente paraestatal), contratada para coordinar la capacitación, tiende a etnicizar los conflictos sociales, a esencializar la diferencia cultural entre mapuche y wingka (no-mapuche) y, de manera correlativa, contribuye a la elaboración de una versión reificada de la cultura mapuche. Veremos que al invisibilizar las condiciones sociohistóricas de producción de la diferencia cultural y al desvincular las producciones culturales indígenas de los mecanismos de sujeción, dominación, enajenación y explotación a los que estos grupos se encuentran sometidos, los agentes a cargo de la capacitación tienden a generar las bases para la etnicización del llamado "conflicto cultural", lo que desemboca en una polarización entre colegas mapuche y no-mapuche de los distintos servicios de salud de la zona intervenida.

Por otro lado, y en sentido contrario a la dinámica de disyunción cultural que acabamos de mencionar, advertiremos que en el transcurso de la capacitación se genera, entre funcionarios mapuche y no-mapuche, un espacio compartido de crítica a la jerarquía del sistema de salud en la cúspide de la cual se ubica tal un dios y amo, el médico todopoderoso. Finalmente, mostramos que además de representar un campo en el cual se desarrollan dinámicas contradictorias, el subcomponente capacitación tiende a transformarse en un espacio de creación y difusión de un conocimiento novedoso sobre la sociedad mapuche, su historia y relación con la sociedad dominante chilena.

\section{La Salud Intercultural según el Estado y sus Críticas}

Según los términos del Reglamento Operativo del Programa de Desarrollo Integral de Comunidades Indígenas, "el fin del Componente de Salud es contribuir a elevar la situación de salud de la población rural mapuche, aymara y atacameña, mediante la eliminación de barreras culturales y la ampliación del acceso físico a los servicios". Pretende inscribirse en la continuación de la política de salud intercultural llevada a cabo por el Estado chileno desde principios de la década de los 90 y consta de cuatro subcomponentes: (1) Desarrollo de modelos interculturales de atención y 
gestión en salud; (2 ) Mejoramiento de la calidad, sensibilidad y pertinencia cultural de servicios de salud en territorio indígena; (3) Fortalecimiento de la medicina indígena; (4) Mejoramiento del acceso y capacidad resolutiva de la red de servicios interculturales.

Lo que se buscó durante la primera fase del Programa de Desarrollo Integral de Comunidades Indígenas (2001-2005) fue "la construcción de un modelo de salud intercultural técnica y socioculturalmente validado" y su incorporación al sistema chileno de salud. Como lo señalaba anteriormente, estos objetivos generales corresponden, grosso modo, tanto a la misión como a las orientaciones definidas por el Ministerio de Salud desde la creación de su Unidad de Salud y Pueblos Indígenas en $1993^{5}$. De manera más específica, el objetivo del segundo subcomponente Capacitación es "la instalación de programas de formación de recursos humanos en salud intercultural, para mejorar la sensibilidad, calidad, pertinencia cultural de los servicios de salud en territorio indígena". Este subcomponente tiene como meta "sensibilizar, informar y capacitar tanto a los funcionarios de los Servicios de Salud asociados a las comunas en que se focaliza el Programa como de los departamentos municipales de salud de las mismas, en la perspectiva de generar cambios en las prácticas de gestión y calidad de atención de salud actuales" (Bid/Mideplan 2001). La responsabilidad de la ejecución de este subcomponente está a cargo de los coordinadores del Programa de Salud y Pueblos Indígenas a nivel de los servicios de salud participantes. Dentro de este subcomponente, se prevé:

el establecimiento de una propuesta metodológica y de contenidos con el propósito de elaborar e implementar un programa de capacitación con pertinencia cultural así como la capacitación del 70\% de los funcionarios, identificados como claves en la atención de salud de la población rural indígena, de la red pública de salud de los servicios de cada región así como también el $90 \%$ de los funcionarios de los servicios de salud municipal, que atiende a las poblaciones antes señaladas (Bid/Mideplan 2001).

Fundamentalmente, las capacitaciones están orientadas a "un cambio en las prácticas de los equipos" (Bid/Mideplan 2001). Se contempla también la organización de un curso de cultura y lengua indígena para formar a 500 funcionarios.

Las críticas vertidas en contra de la concepción de la salud intercultural plasmada en la documentación oficial vinculada al programa Orígenes son múltiples y han sido expresadas públicamente durante los últimos años. Recordémoslas aquí brevemente, pues contribuyen a la construcción de la salud intercultural como espacio de lucha de significaciones y clasificaciones. En primer lugar, se advierte que la salud se encuentra desconectada del resto de los problemas a los que se enfrentan las comunidades indígenas. No está vinculada a la estructura social y económica en su conjunto ni tampoco a asuntos de índole política. Esta versión despolitizada y "aséptica" de la salud entra en contradicción con los resultados arrojados por varios estudios etnográficos llevados a cabo en comunidades mapuche que demuestran que los comuneros indígenas conciben la salud como un hecho social global, relacionado a lo que llaman la "buena vida" (küme mongen), la autodeterminación y el autogobierno (kisu ngünewael) (Boccara 2002, 2004; Boccara et al. 2004).

En segundo lugar, en los documentos producidos por Orígenes se maneja la idea bastante vaga de interculturalidad como comprensión mutua entre culturas diferentes ${ }^{6}$. Lo que sí surge de manera clara a la lectura de la multitud de informes, documentos de trabajo y reglamentos producidos en los últimos años es que la interculturalidad no aparece relacionada al problema de las relaciones de poder entre el Estado chileno y los pueblos indígenas. Mientras los dirigentes, los comuneros y los terapeutas indígenas han hecho hincapié sobre la necesidad de reconocer a los mapuche como sujeto político y jurídico, el Estado se limita a reconocer a la cultura indígena como "digna de respeto". La perspectiva "culturalizante" adoptada por el aparato estatal a través de este programa indigenista de gobierno (perspectiva evidentemente influenciada por la retórica de las agencias multilaterales $)^{7}$ tiende a definir una suerte de "cultura sin pueblo" (Hill 2002). Además, la diferencia cultural no se concibe en tanto como producción histórica (i.e., como el resultado de complejos y múltiples procesos de etnogénesis y etnificación) sino como algo siempre dado. De manera íntimamente vinculada al doble proceso de "culturalización” y despolitización de la salud, se advierte que 
en ningún momento se habla del tema de la autodeterminación y de la autonomía sino que de "autogestión" (Bid/Mideplan 2001), lo cual remite a un ámbito más local así como también a una acción social más acotada. Por lo tanto, se construye y clasifica a "lo indígena" como actor local, aislado y cuya diferencia cultural está dada a priori.

En tercer lugar, el tema de la salud no aparece vinculado a los problemas económicos que afectan a las comunidades. La documentación oficial destaca obviamente el Estado de pobreza y la postergación en que se encuentran los mapuche. Sin embargo, no hace referencia a las causas de la pauperización y marginación de las comunidades indígenas. Aunque muchas de las comunidades involucradas mencionan que sus principales problemas de salud tienen que ver con la invasión de las plantaciones forestales, la contaminación, la usurpación de las tierras ancestrales, la opresión política y la discriminación social, estos aspectos no se incorporaron dentro del reglamento operativo en salud como tampoco figuran en los planes de desarrollo comunitario o en los proyectos de fomento de la medicina indígena. En resumida cuenta, los efectos de estructura social sobre la desigualdad frente a la enfermedad son invisibilizados y la pobreza es aprehendida como un hecho natural y no como un fenómeno social producto de una relación desigual. La precariedad en materia de salud no conduce a hablar de la producción de las desigualdades entre las distintas clases sociales o grupos étnicos, sino que se reduce a un problema de acceso a los servicios ofrecidos o de incomprensión cultural.

Para tomar un ejemplo concreto, constatamos que de los 51 proyectos de recuperación, desarrollo y fortalecimiento de la medicina indígena aprobados por Orígenes Araucanía Sur en 2003, solamente tres hacen referencia explícita a temas de orden político o económico extracomunitarios. Por otra parte, la similitud en los contenidos y las formas estereotipadas de los 48 proyectos restantes hace suponer que estos fueron elaborados obedeciendo a un formato preestablecido y que los dirigentes comunitarios optaron por formularlos de acuerdo a lo esperado por las personas encargadas de gestionarlos. En la gran mayoría de los casos se mencionan como objetivos del proyecto la recuperación de los conocimientos perdidos y la protección de los espacios con plantas medicinales, pero en sólo tres casos se habla de recuperar los espacios (control territorial) con plantas medicinales y proteger el conocimiento (control cultural). De manera significativa, los tres únicos proyectos que se destacan por su originalidad vinculan sus demandas de recursos a problemas de índole política y económica y emanan de comunidades organizadas territorialmente cuyos miembros participan del movimiento social mapuche. El resto de los proyectos, los cuales recibieron un promedio aproximado de US\$ 4,000 cada uno, se inscriben dentro de la línea oficial de la salud intercultural y se atienen al formato establecido.

Otra crítica al abordaje intercultural de Orígenes proviene de un grupo de agentes de salud que hacen notar que la definición de un modelo de salud intercultural de Estado tiende a producir efectos políticos de control y espacialización pues se pretende realizar una encuesta sobre "antecedentes de especialistas de la medicina indígena" y "someter a la medicina mapuche a la legalidad del Estado chileno". Estos hechos fueron denunciados en 2002 por el Equipo de la Unidad de Salud con Población Mapuche del Servicio de Salud Araucanía Sur. En una carta abierta redactada en la ciudad de Temuco y difundida por Internet, los miembros de esa Unidad pionera en la implementación de un modelo de salud complementaria critican al programa Orígenes por haber generado una estructura de intervención paralela que no toma en cuenta su experiencia en salud complementaria así como tampoco el tipo de relación y negociación que esa unidad estableció con las comunidades rurales a lo largo de sus 10 años de funcionamiento (Jelves et al. 2003). Insisten sobre el hecho de que "la medicina mapuche sólo puede fortalecerse en un contexto de autonomía y autodeterminación donde exista control pleno de las comunidades sobre el uso del territorio".

Finalmente, se criticó mucho el hecho de que no hubiera participación real en el diseño del componente salud. He aquí lo que sostiene la Coordinadora Regional de Salud Intercultural en el Marco del convenio MINSAL-MIDEPLAN del programa Orígenes:

No hubo consulta, realmente no... Hubo una visita de una persona de Washington en el MINSAL de Santiago, después en el Promap ${ }^{8}$, pasaron por Makewe ${ }^{9}$. Pero participación indígena en el diseño no hubo en absoluto. No hubo participación 
indígena en este componente en general. En el diseño hubo zero participación comunitaria. Y luego cuando nos invitaron para la presentación del programa, hubo mínima incorporación de la validación de la medicina indígena y de la participación de las comunidades en el componente. El tema era modelo, apoyar algunas experiencias de salud intercultural y reproducirla en otros lugares ${ }^{10}$.

Ahora bien, el estudio de la implementación de un modelo de salud intercultural como campo de luchas de significaciones y clasificaciones quedaría incompleto si nos limitáramos a la presentación de las conceptualizaciones de un programa de Estado y de sus críticas generales. Conviene por lo tanto ubicarse ahora en el nivel de la ejecución del proyecto con el fin de considerar la manera como los agentes sociales focalizados (funcionarios públicos, comunidades rurales) y los ejecutores o promotores locales del programa (consultoras, empleados de Orígenes en las regiones, capacitadores, etc.) interpretan y reaccionan al multiculturalismo de Estado, delimitando a su vez, a través de sus acciones y elaboraciones simbólicas, otro espacio o subcampo de luchas de significaciones y clasificaciones.

\section{La Salud Intercultural como Espacio de Etnicización y Reificación de la Cultura: EI Taller de Capacitación de Carahue (5 de noviembre 2003)}

Para implementar los talleres de sensibilización del año 2003, el Programa Orígenes Araucanía Sur dispuso de US\$65,000. El objetivo era capacitar a 350 funcionarios trabajando en el ámbito de salud (auxiliar de posta, enfermero, matrón, nutricionista, médico, asistente social, chofer) en 14 comunas de la Provincia de Cautín de la Novena Región en un período de dos meses y medio. Entre los 350 capacitados, se calcula que hubo un total 150 personas de origen mapuche y que casi todos provenían de la planta baja del sistema (i.e., auxiliares paramédicos y administrativos). Con respecto de la capacitación de los funcionarios de la comuna de Carahue que nos interesa aquí, se desarrolló entre los meses de agosto y noviembre del año 2003. Se efectuó en 17 sesiones y duró un total de 40 horas. Un promedio de 50 personas asistieron a esos talleres sobre un universo total de 152 personas pertenecientes o bien al Servicio Nacional de Salud o bien al Departamento de Salud Municipal. Ello demuestra que la tasa de participación fue bastante alta. Sin embargo, el Informe de ejecución del proyecto de intervención institucional en salud intercultural (Axxiona 2003) señala la poca asistencia y colaboración de los médicos y directivos, estando sobre todo representado el cuerpo de los auxiliares paramédicos ${ }^{11}$.

A continuación nos enfocaremos sobre la presentación del último taller durante el cual se trató de recapitular los conocimientos adquiridos en el transcurso de las sesiones anteriores. El objetivo general fue fomentar el debate entre los participantes con el fin de generar propuestas sobre el diseño de un modelo de salud intercultural. El debate que se desarrolló durante la mañana del 5 de noviembre del año 2003 nos interesa aquí pues permite ver in situ cómo se entiende y define la salud intercultural y cómo los distintos agentes perciben la diferencia cultural. Vayamos pues con la presentación de este taller.

La consultora Axxiona elegida para llevar a cabo la organización de los talleres de capacitación tiene como especialidad el desarrollo humano. A pesar de tener poca experiencia en el tema de la salud, consta de un staff bastante dedicado y sensible a la "causa mapuche", o por lo menos convencido de que el multiculturalismo fomentado por el gobierno de Chile es el camino a seguir para construir un país más moderno, humano e integrado. De hecho, el antropólogo de Axxiona que anima el debate ese día no esconde sus opciones ideológicas, insistiendo sobre la importancia de respetar y valorar las diferencias culturales. Citaré a continuación lo que los agentes de salud y el capacitador de Axxiona dijeron durante el taller. Veremos, a través de la transcripción de los intercambios verbales, en qué medida la salud intercultural se está constituyendo y construyendo como un espacio de definición de la diferencia cultural, de etnicización de los conflictos sociales y de negociación de los nuevos roles sociales en un contexto ideológico cada vez más marcado por la retórica multiculturalista de incorporación de la diferencia en la economía política nacional por un lado y por la cultura neoliberal de responsabilización de las personas por el otro. En fin, observaremos que la definición de un modelo de salud intercultural pasa por la formación de un nuevo 
campo de significación y de relaciones de poder dentro del cual los agentes de la salud se ven constreñidos a tomar posiciones y expresar opiniones tanto en función de sus intereses individuales y grupales como en función de las identidades étnicas y sociales a las cuales se encuentran adscritos vía la nueva visión y división multiculturalista y neoliberal del mundo social. De suerte que la salud intercultural no es solamente "una nueva manera de atender a los usuarios mapuche para mejorar su calidad de vida" o de "encontrarle un lugar digno al sistema médico indígena". Es también una nueva manera de gestionar la diferencia cultural, de asignar identidades, de clasificar a los grupos así como de responsabilizar a los funcionarios de la salud en el marco de la reforma general del sistema de salud. Remite tanto a una nueva aproximación a las luchas sociales en clave cultural y étnica como a una nueva gestión de los servicios públicos. He aquí las palabras de introducción del empleado de Axxiona quien animó el debate de principio a fin:

Axxiona: El servicio de salud ha hecho muchos esfuerzos en términos de recursos. Estamos finalizando un proceso y la idea es que al final de este proceso ustedes pudieran incorporar algunas nociones, alguna información, algún conocimiento. Al final, con ese conocimiento incorporado, la idea es que pudieran ustedes hacer sugerencias, retroalimentar el sistema para que aquellas cosas que aparecen como desafíos puedan tener, desde la parte de las autoridades, todas las decisiones compatibles, los recursos y los ajustes que permitan hacer cosas nuevas en el ámbito de lo que hemos estado conversando. Así que la reunión de hoy es para que ustedes elaboren, de la manera más participativa posible, sugerencias que permitan a la dirección del servicio orientar sus decisiones sobre estos asuntos. Es por eso que nosotros hemos querido dividir a la comuna por grupos, para poder hacer la reflexión un poco más acuciosa. Yo quiero hacer un resumen general de lo que hemos visto durante la capacitación. Hemos visto diferentes módulos. La idea fundamental era reconocer que la calidad del servicio depende de las expectativas de los clientes, o de los usuarios y no tanto de cómo hacemos las cosas. Hay una serie de criterios, parámetros técnicos que nosotros utilizamos para trabajar y somos rigurosos en eso y sabemos que lo hacemos bien. Pero, sin embargo, encontramos que hay gente que no se siente satisfecha, a veces no se siente bien atendido por nosotros, aun cuando nosotros intentamos hacer todo lo que creemos que es correcto. Parece ser que además de hacer las cosas como sabemos que hay que hacerlas, también hay que incorporar la visión, la experiencia, la opinión del usuario y tratar de ir viendo cómo conseguimos una negociación entre lo que nosotros estimamos es lo correcto y lo que requiere efectivamente el usuario. Esto es super importante porque cuando hablamos del usuario mapuche lo que parece correcto para nosotros es bastante distinto de lo que pudiera aparecer para un usuario mapuche. Bueno, como las personas son distintas entonces las expectativas son distintas. Y aquí estamos con la discusión que tuvimos en distintas comunas sobre si a todos los tratamos igual o hacemos diferencias. Finalmente, lo más importante es reconocer los distintos tipos de personas a partir de las diferentes expectativas que tienen. Estas son las ideas generales que a nosotros nos gustaría que ustedes ampliaran. Porque el usuario mapuche es diferente. Por eso hicimos un módulo que estuvo a cargo del Laboratorio Mapuche para que ustedes pudieran entender la diferencia. No hay una diferencia porque sí. Ellos tienen una cosmovisión y una religión distinta, una medicina distinta, tienen una organización social diferente y han tenido una serie de transformaciones a propósito del contacto que han tenido con la sociedad chilena (...) de la cual formamos parte nosotros como sistema, ¿no cierto? Por eso estamos aquí haciéndonos cargo de tratar de resolver este problema, ¿no? Bueno, en el tema de cosmovisión y religión mapuche la idea era que ustedes pudieran reconocer en el usuario mapuche los aspectos que lo definen como usuario significativamente distinto al 
resto de los otros. Acceder a un conocimiento que ayude a mejorar la comprensión del usuario mapuche y acceder a un conocimiento que los lleve a ajustar la atención general a los criterios que sostiene el usuario mapuche. Estas son las ideas generales, no les voy a hablar de los contenidos pues ya los revisaron... También vimos algo de medicina mapuche. Y la idea básica de ese módulo era conocer las formas como el usuario mapuche entiende el proceso de salud-enfermedad, distinto como lo entendemos nosotros, bastante más integral, hay una noción de equilibrio, está involucrada la relación con el medio ambiente, con la familia, con la comunidad, son aspectos importantes en el momento de considerar el proceso de salud-enfermedad, distinto como lo hacemos nosotros en el sistema (...) chileno digamos. Reconocer algunas formas de enfermedad existentes en la medicina mapuche es identificar algunos recursos de salud dentro del sistema de salud mapuche y tenemos básicamente la figura de la machi.

El capacitador concluye su prólogo para dar lugar al trabajo en grupo que tiene como objetivo generar "más que aseveraciones de sentido común de ciudadano, una respuesta un poco más sofisticada incorporando las discusiones, la información y el conocimiento" que estuvieron revisando. $\mathrm{Al}$ terminar el trabajo en grupo, la presentación de las propuestas se inicia. Transcribo a continuación los momentos que me parecen ser los más interesantes y significativos de las tématicas e interpretaciones que emergieron. Estos extractos son bastante largos pero ricos en información en cuanto a lo que termina "saliendo" de las mentes de unos colegas que dejan caer las máscaras para adaptarse a las nuevas reglas del juego, al nuevo espacio social de poder y de significación que se ha ido dibujando de a poco, con sus relaciones de fuerza y sus nuevas apuestas (jeux y enjeux).

Una señora, en nombre de su grupo, dice que hay que "humanizar el modelo de atención y tener más conocimiento en cosmovisión mapuche". Otro grupo sostiene que conviene "realizar talleres de capacitación continuo dirigidos a todo el personal médico y paramédico así como también efectuar salidas a terreno". Una funcionaria afirma que "si no hay interés y cambio de actitud, no sirve de nada hacer capacitación". En ese momento toma la palabra un auxiliar paramédico mapuche que trabaja en la costa y que pocos meses atrás no opinaba tan abiertamente con respecto de la necesidad de valorar la medicina mapuche como tampoco criticaba la jerarquía del sistema a pesar de ubicarse en su último escalón. Sin embargo, en un contexto en el cual el hecho de ser mapuche se encuentra revalorizado a los ojos de las autoridades del sistema de salud, este auxiliar habla con claridad: "Pienso que debe haber más cooperación de parte de las autoridades. Sería importante conocer a la machi, a su ruca, a su ceremonia. No sacamos nada en capacitarnos si no hay salida a terreno para conocer mejor a la gente". Empieza entonces a emerger el tema de la diferencia y de la igualdad de trato. Una señora entra de lleno en el tema: "La Constitución dice que Chile es un país unitario entonces ¿por qué estamos haciendo diferencias para las personas que viven dentro de un territorio que rige la Constitución política y leyes distintas para los pueblos?". Luego conecta el tema de la diferencia cultural al tópico de la pérdida cultural:

A lo mejor los mapuche no quieren recuperar su cultura. Hay algunos quizás que quieren pero no es la mayoría. Yo he entrevistado a un montón de mapuche y lo único que saben es que son lafkenche. Entonces nosotros los wingka nos estamos llenando de información para tratar de entender al pueblo mapuche, pero ¿qué pasa si el pueblo mapuche no quiere conocer su cultura?

Otra funcionaria corrobora los dichos de su colega: "Es cierto lo que acaba de decir, porque entrevisté a varios mapuche y lo único que conocen es el nguillatun, pero lo demás nada, no tenían ni idea del pueblo al que pertenecían". Una vez lanzado el tema de la diferencia y de la unidad en términos culturales y esencialistas, la gente empieza a declinarlo sobre todos los registros. He aquí lo que sostiene un funcionario que se define como creyente:

En general, la mayoría de los mapuche que entrevisté se declaran mapuche cris- 
tianos, creyentes en Dios. La cosmovisión que nosotros mismos vimos en el taller nos lleva a un punto donde ellos, no sé (...), la cosmovisión original no se identifica con Dios. O quizás tiene un concepto de Dios totalmente diferente que tenemos nosotros. Pero creo que el $80 \%$ del pueblo mapuche en este instante se declara cristiano. Por lo tanto nosotros, si queremos hacer algo, vamos a tener que hacer algo mirando desde esa perspectiva. No podemos llegar y hacer algo como por ejemplo nos dijo José Quidel que nos trató de volver a las raíces, hacer todo lo que hacía años atrás el pueblo mapuche. Sino que tenemos que aplicarlos a la realidad.

Frente a la deriva esencialista que toma el debate, una funcionaria mapuche lo recentra inmediatamente sobre el tema de la discriminación histórica, de la imposición de un arbitrario cultural y de la política interna de las comunidades:

\begin{abstract}
Debemos volver hacia atrás y ver cómo históricamente ha sido discriminado el pueblo mapuche, la razón por la cual se niega a ser mapuche y por qué ahora las sectas religiosas están invadiendo las comunidades. Por ejemplo, los jóvenes mapuche, ellos se avergüenzan o bien porque han sido discriminados o porque los papás se criaron en la discriminación. Entonces los padres, para que no les pasara lo mismo, les enseñaron castellano y muchos se fueron a las iglesias religiosas. Yo como mapuche creo que es un tema que hay que conversar con los dirigentes.
\end{abstract}

Desde ahí, el debate se desvía hacia el problema de la mediación en la atención al paciente, pero vuelve en seguida sobre el tema de la diferencia cultural para desembocar sobre la tématica del conflicto cultural. Una funcionaria mapuche del hospital de Carahue aparentemente al tanto del protocolo de presentación indígena (pentukuwün, chalitun) sostiene que es "fundamental saludar, dar un cordial saludo a la gente para que se sienta incorporada cuando vienen a atenderse". Afirma que "la persona que habla mapudungun es el mejor mediador en estos ca- sos". Un hombre reacciona en seguida diciendo que "hay que dar la mejor atención posible no sólo al pueblo mapuche". En este momento, la discusión se pone más tensa cuando una funcionaria no mapuche sostiene lo siguiente:

Si estamos hablando que vamos a ser mediadores, entonces damos por hecho e implícito que hay un conflicto entre ambas culturas. Entonces, creo que no va el término de mediador, más que nada creo que es facilitador, guía u orientador. Porque si no estamos dando a entender que hay un conflicto.

Otra mujer no mapuche piensa que "hay que respetar a todos, que en el curso se ha marcado demasiado las diferencias y que hace falta respetar a todas las culturas". Esta idea es compartida por la mayoría de los agentes de salud no-mapuche e inmediatamente reafirmada por otra funcionaria: Independientemente "de ser mapuche o de ser chileno, ambos somos personas. Se debería respetar a las personas. Todos respiramos, vivimos, comemos... Lo único que tienen diferente los mapuche es el apellido". De a poco, dos grupos se van delineando entre los asistentes, los mapuche y los wingka. Esta demarcación remite al hecho de que un grupo sufre de la discriminación y de la violencia simbólica cuando el otro no la percibe como tal o no reconoce que incluso llega a ejercerla dado que recurre a una serie de justificaciones "objetivas" que legitiman su manera de actuar y de pensar. Pero en ese momento crítico de reconfiguración del sistema de representación y valoración dominante, los agentes de la salud mapuche no dejan pasar la oportunidad de denunciar y develar los mecanismos sutiles de la discriminación y humillación cotidiana a la cual están sujetos: "lo que veo es como el mapuche llega a una atención, hay una diferencia. Atienden al no-mapuche primero. Hay marginación. Hay diferencia en la parte educacional. No todos los mapuche podemos llegar a la escuela, pienso que hay diferencias. Para respetar, tienen que conocer a la cultura" sostiene enfáticamente un funcionario mapuche. Un joven auxiliar de posta mapuche señala a los wingka presentes que antes de hablar hay que conocer la realidad en terreno y que "no se puede decir que los jóvenes no están interesados en aprender su cultura". Concluye de la ma- 
nera siguiente: "Lo que se define es que somos dos culturas diferentes y que existe una cultura mapuche que sí se puede complementar". A esta altura del intercambio, el debate se pone aún más denso cuando una mujer se lanza con vehemencia en contra de la política de discriminación positiva entablada por el Estado chileno en los ámbitos de la salud y de la educación. Ella habla desde su condición de mujer wingka pobre que también sufre de la humillación y discriminación:

Lo que estás hablando es que a lo mejor hace 20 años atrás había racismo, una diferencia entre mapuche y wingka, pero hoy día jes casi todo al revés! Porque lo que tú hagas: primero es el mapuche y después el wingka. Si pides un crédito y eres mapuche te lo dan al tiro. ¡Entonces de qué discriminación podemos hablar siendo que en este momento hay una diferencia pero notable entre wingka y mapuche, con una aceptación más de mapuche que de wingka! En el hospital de Imperial no hay atención al wingka antes y del mapuche después. ¡Incluso se atiende a los mapuche primero en la mañana para que se vayan tranquilamente en el bus de la tarde! ¿Así que qué diferencia puede haber? ¡Ahora nosotros los wingka somos a los que nos están dejando al lado! En la universidad tienen de todo, tienen hogar, becas, este y este otro. A mí no me dieron nada, tenía 6 de promedio...

Por primera vez, mientras una parte de la asistencia se pone a aplaudir, múltiples y desordenados comentarios se desatan. El capacitador se ve obligado a intervenir para restablecer el silencio. En esa atmósfera conflictiva, ¿quién mejor que un hombre de fe para conciliar los espíritus? Es así como el funcionario creyente vuelve a la carga con una postura de unión en Dios. Introduce sin embargo un elemento que no se ha tocado desde el principio, a saber: la existencia de diferencias muy marcadas entre las distintas clases sociales que conforman la sociedad chilena. Dice con voz apacible aunque con mucha autoridad y en forma de condena moral:

Creo que estamos en un taller de interculturalidad y que no podemos llegar a este nivel. Aquí tenemos que ser muy objetivo. Yo creo mucho en Dios. Ante Dios somos todos iguales. Somos todo un pueblo, somos chilenos y somos chilenos. Hay que dejar una cosa clara: nosotros no podemos hacer diferenciaciones. Nosotros tenemos que aceptar al mapuche como un hermano más. Incluso de repente hay muchas diferencias entre los diferentes estratos sociales de nuestras comunidades, de nuestra sociedad. El rico, el pobre, diferencias que son más marcadas y más fuertes. Entonces creo que tenemos que terminar con estas conversaciones y todo lo contrario tenemos que hacer conversaciones donde nos unamos, todos por igual.

Surge entonces el tema de la deuda del Estado chileno: "Hay una deuda histórica para con el pueblo mapuche", dice un hombre mapuche, y continúa: "¡Hubieron (sic) torturas, se mataron a sus longkos [líderes] para que se debilitara!" Una funcionaria mapuche contradice a la colega cuya diatriba fuera aplaudida pues, según ella, la afirmación según la cual todos los mapuche reciben beneficios del Estado es errada. Una mujer nomapuche le da entonces la vuelta al tema de la discriminación acusando a los mapuche de ser responsables de la mala atención que se les da en los servicios públicos así como del desconocimiento de su cultura por parte del resto de los chilenos:

A lo mejor se debe a que los mismos pueblos originarios tienen la responsabilidad de no haber dado a conocer su cultura, su conocimiento, su modo de vivir. Y por eso es un gran desconocimiento de eso, porque si hubiese sido así a lo mejor los que habitamos en este país hubiésemos estado al unísono defendiendo a nuestra cultura, porque todos somos parte de la cultura del mapuche.

Una mujer mapuche intenta explicar las razones de este desconocimiento vinculando el problema de la pérdida cultural al fenómeno más general de la colonización y opresión:

Lo que pasa es que el pueblo mapuche perdió su identidad. Entonces ni los mis- 
mos mapuche saben que es su camino. Ha cambiado la religión. El mapuche perdió su bandera. Por ejemplo si le pedimos al mapuche cuál es su bandera, no sabe. Acá nos pisotearon, nos corrieron.

En este instante, interviene por primera vez un médico para recentrar el debate sobre el tema de la atención al paciente/cliente:

La atención de personas sea en salud, sea en el banco, sea en un negocio, el trabajar con personas siempre va a ser difícil. Los que prestamos servicio en general tenemos que conocer a las personas que atendemos. En general, por su formación como chileno, uno conoce la religión católica, conoce a los evangélicos, un poco a los masones, pero tiene nulo conocimiento de la religiosidad mapuche y de una cultura que es bastante diferente o bastante menos homogénea a lo que uno conoce como chileno de las distintas religiones. Entonces, el hecho de que en esta capacitación le han introducido a uno algunos conceptos de la cultura mapuche, tenemos que incorporarlos a nuestro trabajo diario. No debemos volvernos mapuche, sino que incorporar estos conocimientos para que ellos se sientan mejor. Pero así como uno trata de atender a los niños, a los abuelitos o a la gente de otra religión. Saludar en mapudungun, despedirse en mapudungun para que ellos se sientan un poco mejor. No debemos tratar de cambiar el mundo. Más que enfrentarnos en una discusión de compensación histórica - te dan más de esto, te dan más de este otro- nada más hay que tratar de ser un poco más intercultural en el sentido de comprender a las otras culturas y de no atropellarse.

Desde su posición social dominante y desde el saber biomédico legítimo, el médico evacua el tema político, no habla de la complementación de los modelos médicos y, en una analogía significativa, ve en los mapuche una minoría comparable a los niños o ancianos. Avisa a la gente del peligro y de la inutilidad de querer cambiar las cosas o ponerlas en perspectiva histórica. En fin, desde un enfoque estrictamente médico (i.e., neutro, científico, autorizado) afirma que es necesario tratar de incorporar al "cliente" mapuche al sistema médico dominante para que pueda de una vez por todas mejorar su calidad de vida. Después de más de una hora de debate, el capacitador de Axxiona retoma la palabra en un intento de recapitulación:

¿Se dan cuenta que mientras estamos en los grupos hay un consenso tácito pero que cuando empezamos a excavar salen cuestiones de fondo y posiciones distintas? Es porque estamos representado aquí gente que es mapuche y gente que no es mapuche. Queda mucho para tener un trato intercultural. Nosotros hemos optado por una opción con la cual hemos tratado de estar influyendo en las opiniones de ustedes. ¿Cuál es la opción del equipo? De que hay una diferencia. No a favor o en contra, la valoración es tema de ustedes. Pero las diferencias no pueden ser negadas. Y lo que ocurre es que cuando uno trata de hablar que hay que reconocer a todos por igual, ese que somos iguales está en base a ciertos parámetros que unos definen qué es lo que ser igual. Y ahí nos ponemos a discutir. De ahí viene la dificultad. De ahí viene el conflicto. Por eso hablamos de mediadores parece ¿no?... No sé si ustedes acá percibieron un conflicto, no en el sentido de que nos agarremos del moño digamos, sino en sentir de que hay una posición, hay otra, hay un otro punto de vista que en algunos aspectos se contraponen. No sé si se entiende a lo que voy. Con esto quisiera dejar asentado el conflicto.

Como podemos constatar, múltiples son los temas que desde una perspectiva sociológica vale la pena destacar de este taller. Focalizaremos nuestra atención sobre el papel de la agencia de capacitación y la manera como dirigió e influyó sobre el contenido del debate y la demarcación de los grupos en presencia.

Cabe señalar, en primer lugar, que el antropólogo de Axxiona tendió, a lo largo del taller, a etnicizar las luchas sociales y las identidades. Insistió sobre la diferencia. Habló incluso de la cultura o de la gente mapuche como significativamente diferen- 
te. No tomó en consideración las intervenciones que ofrecían una lectura más social de lo que él no vaciló en llamar "un conflicto cultural". Enfatizó el hecho de que la comunidad de funcionarios se hubiera dividido en dos grupos y que esto, de cierto modo, era lógico, normal. No se interesó por las alianzas transversales, las identidades múltiples, las lógicas sociales transculturales. Todo en el taller, desde la primera hasta la última sesión, tendió a sobredimensionar la diferencia cultural a través de la erección de fronteras herméticas. En este sentido se puede afirmar que la política multicultural o intercultural del Estado tal como se actualiza a nivel local produce y esencializa lo étnico, etnifica.

En segundo lugar, es dable observar que el capacitador se presentó como la voz oficial. Habló con la autoridad que le confiere el hecho de ser un empleado (aunque temporal y precario) del Estado. Discurrió desde la verdad del neoindigenismo multicultural e intercultural oficial. Tendió por lo tanto a valerse de una posición epistemológica que le permitiera abarcar todos los puntos de vista para transmitir "la verdad objetiva" sobre los problemas étnicos y la manera de resolverlos. $\mathrm{Al}$ dirigir el taller en el sentido de una culturalización de las relaciones sociales, obligó a los diferentes actores a definirse únicamente en función de su supuesta identidad étnica y exclusivamente a favor de uno u otro sistema terapéutico. De ahí la formación de dos grupos étnicamente delineados: los mapuche y los wingka. Al decir esto, no pretendemos negar la existencia de la discriminación hacia los mapuche como tampoco estamos desconociendo el hecho de que las diferencias culturales contribuyen a la formación de grupos e identidades. Nuestra intención, como en el punto anterior, es hacer notar que al conectar todo tipo de problema social o económico a la especificidad cultural de un grupo clasificado como esencialmente diferente, se tiende a etnificar este grupo así como a etnicizar los conflictos sociales. El capacitador buscó definir una cultura mapuche pura, prístina, auténtica. No se refirió a la lógica de incorporación que se ubica al principio de la producción y reproducción de la máquina social indígena $^{12}$. No hizo referencia alguna a las formas indígenas del mestizaje o a la manera como la sociedad mapuche ha tendido a perpetuarse a través de préstamos culturales, adaptaciones y reconfiguraciones identitarias. No generó ningún tipo de conexión entre los grupos en conflicto como tampoco hizo referencia a las prácticas terapéuticas híbridas de las personas no-indígenas sino que subrayó y acentuó las diferencias. Al trazar límites culturales rígidos entre este grupo social y el resto de la sociedad chilena, participó de la formación de la creencia en la existencia de un grupo étnico hermético y homogéneo. Tendió a naturalizar la dicotomía entre tradición y modernidad e interpretó la contradicción entre la biomedicina y las terapias tradicionales como un hecho natural y no como construcción social ${ }^{13}$. En breve, contribuyó a reificar los grupos sociales a partir de sus adscripciones étnica y cultural, dejando escapar la complejidad de las lógicas sociales mestizas, interculturales, híbridas, así como también el hecho de que la única ley que conoce la demanda terapéutica, indígena o no, es que todo sirve, vale decir, que todos los medios que permiten sanarse son susceptibles de ser usados por los enfermos (Fassin 2000:96). Una de las consecuencias más directa de la aplicación de este tipo de marco interpretativo culturalista y etnicista es que conduce a desvincular las desigualdades de la estructura socioeconómica a la vez que no permite dar cuenta de la manera como la situación de postergación y pobreza influye en las producciones culturales, pues en el sistema de representaciones mapuche, la noción de wingka no sólo remite a una persona o un grupo de cultura diferente sino que también a un estatus económico y político dominante definido desde el habitus étnico de dominado de los grupos indígenas (Boccara 2000; Boccara y Seguel 1999; Kellner 1993).

\section{La Salud Intercultural como Campo de Luchas Simbólicas}

Poco tiempo después que finalizara la primera fase de capacitación a funcionarios públicos de la Novena Región, entrevisté a Ingrid Quintana ${ }^{14}$. En ese entonces, ella se desarrollaba desde poco menos de dos años como Coordinadora de Capacitación en Salud Intercultural en el Servicio de Salud Araucanía Sur. Nacida en una comuna de la Novena Región y criada por sus abuelos en una comunidad mapuche rural, egresó de la carrera de antropología de una Universidad del centro sur del país antes de trabajar en una ONG mapuche y luego en la SEREMI de Salud de la misma región. Becada de la Fundación Ford en el momento de la entrevista, forma parte de esta nueva generación 
de profesionales mapuche que empezó a emerger en la segunda mitad de los años 1990. En marzo de 2002 presentó sus antecedentes laborales y académicos a la Intendencia de la Novena Región para un puesto de trabajo en el Servicio de Salud Araucanía Sur. No estaba al tanto de que concursaba para ocupar el puesto de Coordinador de Capacitación Intercultural del nuevo Programa Orígenes. Lo único que sabía era que se trataba de dirigir un programa de capacitación en el Servicio de Salud Araucanía Sur. Según ella, la eligieron no sólo porque era antropóloga y tenía experiencia laboral en el ámbito de la salud, sino también porque era mapuche hablante. Aceptó trabajar en el entonces controvertido programa Orígenes ya que como antropóloga "no tenía muchas alternativas laborales" pero también porque consideraba que este programa del BID/MIDEPLAN no era "ni mejor ni peor que los otros dispositivos de intervención estatal en las comunidades mapuche". Afirma sin embargo que en lugar de llamarse Programa de Desarrollo Integral para Comunidades Indígenas, debería denominarse "Programa de desarrollo integral para partidos políticos y cuoteos". Considera que este programa representa una falta de respeto enorme para con los mapuche pues por cada proyecto se otorga un promedio de dos millones de pesos, lo cual es irrisorio si se toma en cuenta el número de familias por comunidad. Además, según ella, este programa niega las potencialidades de las comunidades pues hay personas capacitadas en los lof (comunidad) que no pueden trabajar directamente para su comunidad. Las consultoras contratadas vienen de afuera y es imprescindible cumplir con los procedimientos del programa. Considera que no hay nada nuevo en Orígenes. Para ella, se implementó porque el Estado chileno, que obedece al mercado mundial, ve en los mapuche un obstáculo al desarrollo. Pues al cortar las carreteras, realizar recuperaciones de tierras, luchar para sus derechos colectivos, y oponerse a que las forestales sigan extrayendo madera, las organizaciones indígenas tienden a perturbar el asentamiento de un modelo de desarrollo neoliberal y depredador. En fin, sostiene que Orígenes es una forma más de "enmendar, engañar, desviar y desvirtuar el proyecto autonomista de los mapuche".

La opinión radicalmente crítica de Ingrid con respecto de Orígenes me lleva a preguntarle cómo concibe su papel dentro de un programa que aborrece. Me contesta que aceptó desarrollarse den- tro de este marco institucional porque pensaba que ofrecía una oportunidad para abrir espacios y tener un impacto real en las mentes de la gente. Afirma que el hecho de tener la posibilidad de hacer capacitación implica conquistar un espacio público hasta ahora vetado a los mapuche. Significa también romper con la invisibilidad a la que fueron reducidos los pueblos nativos desde su derrota militar. Pero hay más que eso. Trabajar en capacitación implica entrar en rebelión contra el orden simbólico dominante y poner en tela de juicio los prejuicios más arraigados en el sentido común criollo. En primer lugar porque ofrece la oportunidad de demostrar que los mapuche son capaces de ocupar puestos de decisión y administrar proyectos serios. En segundo lugar, porque permite darle legitimidad al saber mapuche y otorgarles autoridad a las voces de los profesionales mapuche. Pues hablar desde el Estado, como funcionario contratado por el Estado, en el marco de un programa de Estado confiere al saber y al discurso de los profesionales mapuche una autoridad de la que carecían hasta ahora.

Para llevar a cabo los talleres de capacitación Ingrid contrató los servicios tanto de una consultora (ver más arriba) como de un grupo de reconocidos profesionales y sabios mapuche. Con estos últimos definió varios módulos de estudio siempre teniendo en mente el imperativo de romper con el orden simbólico dominante que ubica a los mapuche en una posición subalterna vía la imposición de un sistema arbitrario de dicotomías arbitrarias (religión cristiana/magia indígena, historia criolla/leyendas nativas, nación chilena/grupos originarios, Estado chileno/comunidad mapuche, biomedicina occidental/brujería india, conocimientos científicos objetivos/supersticiones primitivas, etc.). El primer folleto aborda el tema de la historia mapuche. Ingrid afirma que "no se trataba de repetir la historia oficial que se cuenta en los libros o en los textos escolares", sino más bien de "contar la historia desde el punto de vista mapuche para provocar un impacto real entre la gente". Es así como las mitologías constitutivas del imaginario nacional chileno se encuentran deconstruidas a través la revisión de los principales hitos de la historia nacional mapuche. Lejos de haber sido incorporados pacíficamente al Estado-nación chileno como lo afirma la historiografía dominante ${ }^{15}$, el pueblo mapuche aparece como un pueblo derrotado que perdió su soberanía política a tra- 
vés de la conquista militar de sus territorios por los ejércitos chilenos. A diferencia de la gloriosa historia del progreso contada en los mejores libros de historia de la nación chilena, los fascículos distribuidos durante los talleres enfatizan la violencia, usurpación y el engaño utilizados por los distintos gobiernos de la segunda mitad del siglo XIX y de principios del siglo XX para incorporar las tierras aún libres de un pueblo hasta entonces soberano y rico. En fin, contra la retórica del progreso unilineal y la visión teleológica de la construcción del Estado-nación, los profesionales mapuche escriben una historia de enajenación y represión contra un pueblo soberano que no sólo poseía tierras sino que territorios, organización política y riquezas materiales. De suerte que a través de esta nueva historia, el Estado chileno no aparece como el gran salvador y civilizador que viene a arrancar unos indios primitivos de su miseria material y moral, sino como un usurpador y violador de los derechos humanos, políticos y colectivos de un pueblo que precede tanto a la nación criolla (ámbito cultural) como al Estado chileno (ámbito político). Incorporando los avances de los estudios etnohistóricos y etnológicos publicados en la década de 1990, estos folletos entregan además una visión de lo político desde el pensamiento indígena. Es así como se insiste sobre la existencia de una institucionalidad socioterritorial propia: lof / rewe / ayllarewe / witranmaри / wallmapu como unidades socioterritoriales mapuche opuestas a la división admistrativa chilena en reservas / comunas/ provincias / regiones / Estado. Se pone énfasis también en la existencia de formas políticas propias de comunicación e información como el trawün, el collautun (reunión política) y el pentukuwün (saludo ritual). Finalmente es dable notar que la escritura de esta historia alter/nativa implica un cambio radical de escenario, un pasaje de lo nacional a lo transnacional. En efecto, según los autores de los fascículos, los mapuche residen en wallmapu que se divide entre el ngülumapu (territorio del oeste, i.e., centro sur del Chile actual) y el Puelmapu (territorio del este, i.e., las Pampas y el norte de la Patagonia argentina actual). En esta nueva historia los mapuche son "chilenos por accidente" y su territorio engloba tierras colonizadas por Chile y Argentina. A través de esta nueva visión de la historia mapuche se procede a un doble proceso de deterritorialización / reterritorialización y desnacionalización / renacionalización (Boccara 2005).
El segundo módulo entrega informaciones básicas sobre la cosmovision y religión mapuche. Una vez más, Ingrid insiste sobre la voluntad de poner en tela de juicio el sistema de representación dominante que atribuye un lugar subalterno al conocimiento mapuche. Es así como pone énfasis sobre el hecho de que no se trata de magia o de supersticiones indígenas sino más bien de una verdadera religión. Lejos de la sociología espontánea que ve en el saber mapuche o bien supersticiones primitivas antimodernas o verdades ancestrales milagrosas, la información entregada por el equipo encabezado por el profesional y jefe ritual José Quidel por un lado y por el machi (chamán) Víctor Caniullán, por el otro, restituye toda la complejidad del sistema ritual nativo. Los terapeutas tradicionales (machi o chamán, püñeñelchefe o partera, ngütamchefe o componedor de huesos, lawentuchefe o médica) se encuentran incorporados a la lista de las autoridades de las comunidades (longko o líder sociopolítico del lof, werken o mensajero, genpin u orador oficial). Las enfermedades y prácticas terapéuticas mapuche están clasificadas y descritas como si de patologías y terapias wingka se tratase. Finalmente, se explica en detalles en qué sentido la salud según los mapuche representa un hecho integral vinculado al respeto de normas sociales, a las relaciones entre la comunidad y los distintos seres y entidades que habitan los varios espacios territoriales ( conforman el cosmos (wajontumapu), así como también a la preservación del territorio y de los diversos espacios (menoco, mawida, mallin, pitrantu) en los cuales crecen las plantes medicinales (lawen). En fin, los fascículos dedicados a la medicina y religión mapuche condensan una cantidad de datos etnográficos cuya calidad no tiene nada que envidiar a los libros de etnografía comúnmente usados en las aulas de las universidades chilenas. Lo interesante de estos talleres es que esta información socioetnográfica e histórica de calidad se difunde entre un grupo socioprofesional que hasta entonces manejaba un conjunto de datos estereotipados con respecto del pueblo mapuche y de su cultura, así como también de la historia de las relaciones entre el Estado chileno y los pueblos indígenas. Del mismo modo, el tercer módulo que aborda el tema de la medicina mapuche tiene como objetivo trastornar la dicotomía común entre conocimientos biomédicos por un lado y brujería primitiva o magia ancestral por el 
otro. Calificar al conjunto de conocimientos y prácticas relacionados al ámbito del proceso de saludenfermedad como medicina o sistema médico mapuche implica arrancarlo del ámbito de la brujería para colocarlo al mismo nivel que la biomedicina. Sin embargo, este trabajo de equivalencia tiende a transformar la gestión colectiva de la enfermedad en las comunidades mapuche, participa del proceso de medicalización de los terapeutas mapuche y de normalización de las comunidades. En este caso, el proceso de construcción de la subjetividad mapuche se asocia a un proceso de sujeción a la normativa de Estado sobre el cual volveremos más adelante. Finalmente, el cuarto módulo aborda el tema de la calidad en el servicio (marketing) centrándose en las personas y en el desarrollo individual. Es quizás el único tema que responde directa y explícitamente a los objetivos planteados en el reglamento operativo de Orígenes. Es también el único módulo que obedeció a la nueva manera de concebir el papel de las personas (responsabilización) dentro del plan general de reforma (racionalización) de los servicios públicos. Sin embargo, veremos que en la práctica abrió también una ventana hacia la crítica a la jerarquía existente en el sistema de salud chileno, lo cual generó un espacio compartido de quejas y reivindicaciones entre grupos subalternos mapuche y no-mapuche.

En breve, para -como dice Ingrid- "resituar el estatuto de la religión y de la historia mapuche", hubo que abocarse a una crítica radical de la doxa. El ejercicio de distanciamiento crítico con respecto del peso de las palabras y de la carga ideológica de las nociones empleadas cotidianamente, y por lo tanto pensadas como naturales y neutras, se ubicó al corazón del trabajo de diseño y concepción de los contenidos de la capacitación.

Según Ingrid, el contenido y la configuración de los módulos no respondieron a la política institucional tal como había sido definida por el gobierno de Chile. Señala que no hubo mayor control por parte de Orígenes, lo que le permitió gozar de un amplio margen de maniobra. Así vemos que a pesar del tono conformista del programa, la producción de conocimiento por parte de profesionales y sabios indígenas permitió por primera vez, en un espacio público y con la autoridad y legitimidad que confiere el hecho de hablar con el respaldo de uno de los órganos centrales del Estado (el MINSAL), romper con una serie de dicotomías etnocéntricas que contribuyen a reproducir la dominación simbólica a la cual están sujetos los mapuche. Permitió también, y una vez más a pesar del marco ideológico del Programa, restablecer las relaciones entre la salud y la estructura socioeconómica (explotación económica, dominación social y opresión política). Lejos de adoptar el enfoque general de Orígenes y del gobierno chileno en el cual la salud aparece como espacio bien delimitado y despolitizado dotado de expertos organizados según una jerarquía incuestionable, los capacitadores intentaron elaborar un régimen de representación autónomo. Se lanzaron en lo que podríamos calificar de insurrección discursiva, utilizando, como lo mencionó Ingrid, las propias armas de legitimación del Estado ${ }^{16}$. El membrete del gobierno de Chile, del MINSAL y del MIDEPLAN en los fascículos distribuidos confirió a los contenidos una autoridad que los simples folletos informativos mapuche no tenían. El hecho de hablar en un espacio municipal y de ser presentado por una consultora dirigida por profesionales no-mapuche proporciona un aura que el solo hecho de ser machi o licenciado en educación intercultural bilingüe no permite. Los talleres hicieron posible por otra parte que la población chilena no-mapuche se diera cuenta de que los mapuche existían en sus ciudades. Ya que a pesar de la presencia indígena en las calles de algunos pueblos, muchos se negaban a reconocer el peso demográfico y la vitalidad sociocultural de los nativos ${ }^{17}$. Finalmente, y como lo adelantaba más arriba, los talleres sirvieron para que, a pesar del enfoque etnicista de la consultora y multicultural del programa, los funcionarios subalternos del sistema de salud encontraran un terreno de lucha y reivindicación común. He aquí lo que me relató Ingrid Quintana con respecto de este efecto no previsto o derivado de la capacitación:

Sirvió [el taller] a la gente -mapuche y no-mapuche- para tener mayores armas para luchar contra una estructura jerárquica. A través de los talleres de sensibilización sobre la cultura mapuche, terminamos tocando temas que tienen que ver con toda la gente. Había una cosa en común. Me di cuenta de esto de a poco, trabajando sobre el tema del desarrollo personal. Se trabajó con un psicólogo organizacional. La gente se dio cuenta de la estructura jerárquica y de todo lo que sufre. $\mathrm{Y}$ 
después de esto, después del peso y de la presión ejercida por esta estructura, viene el mapuche... El encargado de limpieza acaba de hacer brillar el piso para que su jefatura lo mire bien o lo mire alguna vez en su vida siquiera, y jllega un mapuche del campo y le planta un zapato lleno de tierra! ¡Y obviamente se va a picar contra la persona que viene del campo!

Finalmente, para terminar sobre este tema de la constitución de la salud intercultural como campo de luchas simbólicas, me permito citar un intercambio entre Ingrid y yo:

Autor: Para concluir, ¿dirías que uno de los efectos de esos talleres fue develar mecanismos de dominación que existían dentro del mismo sistema de salud y permitir a algunas personas sacarse la máscara para aparecer como mapuche públicamente?

Ingrid Quintana: La gente con orgullo y con autoridad se resituaron dentro de la institución, frente a sus pares sobre todo. Porque cuando el docente decía "esto es así", ellos levantaban la mano y daban un ejemplo y así estaban en sintonía con el docente que es investigador, que viene del servicio de salud, entonces los otros 'bang'" [hace un ruido como si de un golpe se tratase para expresar la sorpresa de los funcionarios no mapuche que quedaron aturdidos o pasmados].

\section{De la Etnografía de la Salud Intercultural a la Antropología del Estado Multicultural}

Si tuviéramos que resumir el argumento de este ensayo diríamos lo siguiente: La Salud Intercultural representa tanto un nuevo espacio de lucha de clasificaciones y de formación de nuevas subjetividades como un nuevo dispositivo de intervención del Estado que tiende a extender el dominio de lo político a través del desplazamiento de los límites del espacio privado-comunitario indígena. Por otra parte, en la medida en que tiene como meta contribuir a la legitimación (i.e., validación en la jerga desarrollista) del saber terapéutico llamado tradicional, implica una transformación del mercado contemporáneo de la enfermedad, la me- dicalización y moralización de los terapeutas tradicionales, la profesionalización del conocimiento indígena así como la redefinición de la relación que el indígena tiene con su propio cuerpo. Hablamos aquí de medicalización y de moralización en la medida que consideramos que en razón a la naturaleza de sus poderes y del estatus que se le otorga en su sociedad, el llamado terapeuta tradicional no puede ser considerado como el homólogo del médico occidental. En efecto, el poder del machi o yatiri y de otro tipo de terapeuta indígena es individual, ambiguo, indivisible, indiferenciado e inestable. En las sociedades occidentales, el poder tiende a vincularse progresivamente a una función más que a una persona, se orienta hacia el bien en lugar de permanecer en la indeterminación y se encuentra circunscrito al territorio de la enfermedad, cuando en las sociedades tradicionales era y sigue siendo fundamentalmente indiferenciado (Fassin 1996). Asimismo vemos que lo que está en juego a través de la moralización, medicalización y profesionalización de los terapeutas tradicionales es la recomposición de los saberes médicos tradicionales y la reconfiguración del espacio sociopolítico indígena. Ello desemboca en la emergencia de un nuevo espacio social, el campo médico, que se constituye alrededor del poder de curar y que se encuentra estructurado por las relaciones entre agentes que entran en relación de competencia para captar enfermos y delimitar su nuevo campo de competencia y legitimidad tanto frente a los miembros de su comunidad como frente al Estado que funciona desde ahora como instancia de validación. En fin, el terapeuta tradicional debe demostrar, durante las múltiples reuniones realizadas en el marco de los proyectos de salud intercultural, que no es un "chanta" (mentiroso o tramposo), que sólo se dedica a hacer el bien y que es conocido y reconocido por su comunidad. En este sentido, podemos afirmar que la implementación de la salud intercultural contribuye al proceso de diferenciación de los poderes, el cual conduce a la separación de los campos (salud, economía, educación, etc.). La formación del campo de la salud intercultural no sólo implica la extensión del campo médico a las comunidades indígenas, sino que supone la aparición de una nueva gestión colectiva de la enfermedad y la puesta en marcha de nuevos mecanismos de legitimación. De suerte que se puede afirmar, siguiendo a Didier Fassin, que conviene buscar el origen del go- 
bierno de la vida, del cual la salud intercultural representa sólo un aspecto en el desarrollo de nuevas formas políticas (Fassin 1996:207) ${ }^{18}$.

Por consiguiente, vemos que el asentamiento de la Salud Intercultural va mucho más allá de la simple "implementación de una metodología de atención con pertinencia cultural" en un "escenario caracterizado por el creciente pluralismo médico" (Alarcón et al. 2003). Remite a un tipo de saber/poder que se aplica tanto a las poblaciones indígenas como a los funcionarios de la salud. Tiende a "ampliar el espectro de las intervenciones públicas posibles sobre lo vivo y las poblaciones" (Fassin y Memmi 2004:20) a través de la implementación de nuevas técnicas de atención y nuevas conceptualizaciones de lo social que hacen posible redibujar unas realidades hasta hace poco desconocidas o invisibilizadas por el Estado $^{19}$. Opera nuevos recortes en la realidad social (etnificación) y nuevas zonas de intervención (territorialización) con el fin de mejorar y controlar la calidad de vida de la población indígena. Retomando aquí una distinción propuesta por Michel Foucault entre el poder disciplinario que se ejerce sobre el cuerpo de los individuos y el control que se despliega sobre la población, podríamos decir que este nuevo tipo de poder se ejerce tanto a través de un sistema anatomopolítico, vale decir de unas estrategias y prácticas a través de las cuales el poder modela cada individuo, como a través de una biopolítica, esto es, de una gestión política de la vida de la población indígena ${ }^{20}$. Son estas nuevas modalidades de regulación de las poblaciones indígenas que van más allá de la imposición de un sistema de reglas o de la simple represión de las prácticas y representaciones terapéuticas indígenas que hemos propuesto abarcar bajo el término de etnogubernamentalidad, puesto que contribuyen a formar nuevas subjetividades, a acrecentar la vida, a inducir los usuarios a adoptar una buena conducta, a medicalizar el espacio de las figuras políticas comunitarias, a despolitizar los problemas de salud desvinculándolos de la estructura socioeconómica y a incitar a los individuos a que se gobiernen por sí mismos de la mejor manera posible ${ }^{21}$. Dentro de este nuevo espacio de la interculturalidad en salud, el Estado opera como un escenógrafo que organiza las operaciones de transferencia de legitimidad y de autentificación cultural. Opera a través del control de gestión de la diferencia cultural o más precisamente de la dife- rencia cultural legítima. Es aquí donde podemos observar que el proceso de subjetivación se acompaña de un proceso de sujeción, vale decir, "de la construcción de sí mismo a la vez que del sometimiento al Estado" (Fassin 2004:261). Pues si bien es cierto que la salud intercultural es un espacio de luchas cuya apuesta central es la definición de la cultura indígena auténtica y legítima, no deja de ser un espacio social en el que los agentes se posicionan en una relación de obligación frente al Estado. Siguiendo un vez más a Didier Fassin, diríamos que el espacio de la salud nos incita a prestar atención a la producción de sujetos como realidad política (Fassin 2004:262).

En base al análisis acotado del subcampo de la salud intercultural formularemos algunos principios teórico-metodológicos más generales con respecto a la manera de aprehender el modo de funcionamiento del Estado multicultural.

En primer lugar, nos parece que el multiculturalismo de Estado puede ser definido como nueva arte de gobierno. Vale decir, como una nueva forma de gubernamentalidad de tipo étnico que tiende a extender los mecanismos de intervención del Estado, así como también a generar nuevas subjetividades, nuevos espacios de poder, nuevos campos de saber y nuevos mercados de bienes simbólicos y exóticos en los cuales agentes sociales de un nuevo tipo (etnoburócratas, intelectuales indígenas, dirigentes funcionales, terapeutas tradicionales, agentes estatales y paraestatales, etc.) se enfrentan en torno a la definición de los principios legítimos de autentificación cultural y de visión y división del mundo social.

En segundo lugar, para aprehender el fenómeno del multiculturalismo en toda su complejidad no hay que estudiarlo desde la perspectiva del Estado central concebido como ente abstracto, represor, monolítico y omnipotente, sino que es necesario abordarlo tanto en sus conexiones globales con las agencias multilaterales de desarrollo como en sus relaciones con las agentes regionales y locales. Pues, por un lado, conviene examinar el lugar que llegó a ocupar la noción de cultura en la nueva agenda desarrollista global y las vías por las cuales esta etnogubernamentalidad global ingresa a los espacios nacionales y tiende a producir modernidades regionales o periféricas. Y, por otro lado, se hace necesario explorar las aplicaciones locales y los efectos en terreno del multiculturalismo de Estado a través del doble proceso 
de gubernamentalización de las localidades y de privatización de los mecanismos de control del Estado (Sivaramakrishnan y Agrawal 2003). Se trata por consiguiente de estudiar el multiculturalismo tanto desde abajo, a través de la multiplicación de sus dispositivos pragmáticos, como desde arriba, a través de las determinaciones económicas, políticas y morales de nivel global.

En tercer lugar, y como corolario de los puntos anteriores, hace falta realizar una etnografía del Estado multicultural, es decir, un estudio del Estado en su formación cotidiana, en todas sus ramificaciones y en toda su extensión. Eso implica "desagregar el Estado en la multiplicidad de sus operaciones discretas, en sus procedimientos, representaciones" y ritualizaciones (Blom Hansen y Steputtat 2001). Eso supone también interesarse por los efectos de espacialización, visibilización y etnificación producidos por un conjunto disperso y a veces improvisado de prácticas institucionales y de técnicas de gobierno que ubican al ethnos al centro de sus preocupaciones. Se trata por lo tanto de desnaturalizar al Estado multicultural y de dar cuenta de la conceptualización e implementación del multiculturalismo neoliberal desde varios sitios etnográficos y a través de un análisis histórico del marco de racionalidad política en el cual éstas se inscriben.

Desde esta perspectiva, nos parece que el programa Orígenes representa una estructura regional del sistema global, esto como resultado de la movilización indígena de los años 1980 y 1990, del establecimiento de un nuevo pacto político entre indígenas y Estado chileno en el contexto de vuelta a la democracia (Pacto de Nueva Imperial de 1989, Ley Indígena de 1993, Diálogos Comunales 1999 , etc.) y de la apertura de nuevas fronteras del capitalismo global (tratados de libre comercio, clusters forestal, minero, turístico, etc.). El proceso de difusión del multiculturalismo neoliberal, de producción de identidades y de construcción de culturas remite a un problema de relaciones asimétricas de poder en las cuales los mecanismos de decisión, diseño, control de la información y ejecución desempeñan papeles de importancia. Orígenes fue "marketeado", generó innovaciones institucionales, implicó el asentamiento de nuevos procedimientos y dispositivos de intervención, fomentó discursos y prácticas culturizantes o de autentificación. Con respecto a ello, advertimos que el Estado tiende a ejercer un poder creador a través tan- to de la elaboración de una nueva cartografía de la diferencia cultural como de la definición social legítima de lo que está autorizado a ser, el ser social que es legítimo reivindicar, en contraposición al ejercicio ilegítimo e ilegal de la etnicidad (Hale 2004; Hale y Millaman 2005).

Por consiguiente, para aprehender el funcionamiento de este Estado neoliberal multicultural en toda su complejidad y efectos, nos parece que debemos enfocarlo no como sistema cerrado y siempre dado, sino como conjunto de prácticas y discursos institucionales emergentes que tienen como meta empoderar a los nuevos sujetos para que tengan acceso a mercados, también emergentes, y que aspira a responsabilizarlos a través de la llamada participación social, del fortalecimiento institucional y del aprovechamiento de los distintos tipos de capital (cultural y social) disponibles, otrora considerados una traba a la entrada de los indígenas en la modernidad, hoy visto como un asset $\mathrm{o}$ una ventaja en el proceso de modernización y nacionalización del territorio. Pues ya no se trata de borrar la tradición cultural indígena a través de un proyecto asimilacionista de territorialización de la nación (Bengoa 2000; Boccara y Seguel 1999), o de un proyecto indigenista definido desde el exterior de las realidades indígenas en el marco del Estado de bienestar de políticas económicas marcadas por el keynesianismo y el modelo de industrialización basado en la substitución de las importaciones (Bengoa 2000; Bonfil Batalla 1987), sino más bien hacerla partícipe del proceso de modernización. Pero no cualquier tradición, una tradición funcional, reconstruida, reinventada y refuncionalizada en base a la naturaleza de los nuevos proyectos de etnodesarrollo. Los indígenas responsabilizados deben convertirse en los etnógrafos de su propia realidad. Su saber y sus memorias deben ser entextualizadas, sus redes sociales fijarse en comunidades oficialmente reconocidas y legalizadas, sus terapeutas transformarse en médicos de un nuevo tipo, su patrimonio ser reapropiado en función de una esencialización y naturalización del pasado y de la nacionalización de los mecanismos de identificación en referencia a una memoria patrimonializada vía mecanismos legales (Ayala 2006). Este Estado multicultural que investiga la realidad indígena, que (directa o indirectamente) se hace cada vez más presente en terreno, que se materializa y se produce a sí mismo mediante una serie 
de signos y rituales, y que produce lo indígena a través de rituales públicos, funciona en base a una especie de semiofagia. Es un Estado caníbal que produce, incorpora y digiere al "indio permitido" (Hale 2004) y que, parafraseando a Pierre Bourdieu, contribuye a la domesticación de los dominados (Castro-Lucic 2004).

Esta nueva maquinaria de poder se extiende a través de múltiples encuestas, censos e informes que terminan generando un saber etnoadministrativo sobre las creencias, las condiciones de vida, la salud, los hábitos, las enfermedades y por ende la cultura de las poblaciones indígenas. Desde este punto de vista, se advierte un doble proceso de homogeneización discursiva y político-administrativa por un lado y de multiplicación de los sitios de intervención, de dispersión de las prácticas institucionales y de producción de heterogeneidad identitaria por el otro. Dentro de este nuevo marco ideológico de control pero también de entitlement o reconocimiento de algunos derechos específicos, los indígenas son concebidos como grupos ubicados al margen del mercado. El objetivo del programa Orígenes es capacitarlos y "marketearlos" con el fin de poder integrarlos a la nueva nación de consumidores-ciudadanos a través de la creación de la nueva figura del indígena-proyecto. Con respecto a eso, formularemos la hipótesis siguiente: después del binomio civilizado/bárbaro del siglo XIX y moderno/atrasado del siglo XX, estaríamos entrando en la era del cliente exótico/terrorista fundamentalista de principios del tercer milenio.

Ampliando la mirada y tratando de sacar conclusiones más generales a partir de un caso particular, se podría formular la hipótesis siguiente: la fábrica del multiculturalismo representa una ma- nifestación de la formación del Estado neoliberal caracterizado por la ubicuidad, la dispersión y el asentamiento de tecnologías de saber-poder diferenciadas y "diferenciadoras" (ecogubernamentalidad, etnogubernamentalidad, etc.). Más que gobernar directamente y exclusivamente a través de prácticas y discursos homogéneos y centralizados, el Estado neoliberal, del cual el multiculturalismo constituye sólo una faceta, parece controlar y vigilar sus fronteras y fabricar su imaginario a través de la gubernamentalización de la sociedad civil, de la responsabilización de los agentes sociales y de microoperaciones que tienden a supervisar las intervenciones de agencias paraestatales (ONGs, consultoras, universidades, museos, organizaciones indígenas, etc.). El poder de Estado se encuentra fetichizado a través de escenificación y ritualización, pero se realiza en tanto que autoridad suprema y ejerce toda su eficacia en la medida en que es capaz tanto de invadir como de dejarse permeabilizar por las epistemologías de poder cotidianas (Blom Hansen y Steputtat 2001; Coronil 2001).

Agradecimientos: Mis más sinceros agradecimientos a Eugenio Alcaman, Mario Castro Venegas, Domingo Colicoi, Rainer Hauser, Hilario Huirilef, Jaime Ibacache Burgos, Clodovet Millalen, Yolanda Nahuelcheo, Jorge Neira, Bladimir Painecura, Pablo Porras, Marcela Pizarro, Alonso Raiman, Galvarino Raiman, Eduardo Rapiman, Raúl Rupailaf, Rodrigo Valenzuela y José Quidel. Asimismo agradezco a los evaluadores por sus valiosos comentarios y sugerencias. Este trabajo se enmarca dentro del proyecto de investigación Fondecyt 1070014.

\section{Referencias Citadas}

Agrawal, A.

2005 Environmentality: Technologies of Government and the Making of Subjects. Duke University Press, Durham \& London.

Alarcón, A.M., A. Vidal y J. Neira

2003 Salud intercultural: elementos para la construcción de sus bases conceptuales. Revista Médica de Chile 131:1061-1065.

Ayala, P.

2006 Relaciones y Discursos entre Atacameños, Arqueólogos y Estado en Atacama (II Región, Norte de Chile). Tesis para optar al grado de Magíster en Antropología, Universidad Católica del Norte-Universidad de Tarapacá, Chile.
Axxiona

2003 Proyecto de Intervención Institucional en Salud Intercultural. Informe de Ejecución. Axxiona, Consultores en Desarrollo Humano, Temuco.

Bengoa, J.

2000 La Emergencia Indígena en América Latina. Fondo de Cultura Económica, Santiago.

Bid/Mideplan

2001 Reglamento operativo. Componente salud. Santiago. Manuscrito en posesión del autor.

Blom Hansen y F. Steputtat, editores

2001 States of Imagination. Ethnographic Explorations of the Postcolonial State. Duke University Press, Durham \& London. 
Boccara, G.

1999 El poder creador. Tipos de poder y estrategias de sujeción en la frontera sur de Chile en la época colonial. Аnиаrios de Estudios Americanos LVI-1:65-94.

2000 Antropología diacrónica. En Lógica Mestiza en América, editado por G. Boccara y S. Galindo, pp. 21-59. Universidad de La Frontera/Instituto de Estudios Indígenas, Temuco.

2002 The Mapuche people in post-dictatorship Chile. Études Rurales 163-164:283-304.

2004 Del buen gobierno en territorio Mapuche. Notas acerca de una experiencia en salud complementaria. Cuadernos de Antropología Social 20:113-129.

2005 The Brighter side of the indigenous renaissance: Mapuche symbolic politics in today's wallmapu (i.e. Chile and beyond). Ponencia presentada en el Department of Sociology and Institute for Global Studies, University of Minnesota, Minneapolis.

Boccara, G., editor

2000 Lógica Mestiza en América. Universidad de La Frontera, Temuco.

2002 Colonización, Resistencia y Mestizaje en las Américas. Abya Yala/Instituto Francés de Estudios Andinos, Quito/Lima.

Boccara, G., M. Castro y E. Rapiman

2004 Küme Mongen ka Kisu Ngünewael Lafkenmapu Meu. Hacia la Salud Complementaria en Territorio Lafkenche. Ministerio de Salud/Unidad de Salud con Población Mapuche, Temuco.

Boccara, G., J. Ibacache y J. Ñanco

1999 Modelo de lógica intercultural o modelo de salud de lógica indígena. Algunas reflexiones sobre la noción de interculturalidad. Tercer Encuentro de Salud y Pueblos Indígenas, pp. 99-102. Ministerio de Salud, Temuco.

Boccara, G. e I. Seguel

1999 Políticas indígenas en Chile (siglos XIX-XX). ¿De la asimilación al pluralismo? Revista de Indias 217:741-774.

Bonfil Batalla, G.

1987 México Profundo. Ciesas, México.

Bonnevitz, P.

2006 La Sociología de Pierre Bourdieu. Ediciones Nueva Visión, Buenos Aires.

Castro-Lucic, M., editora

2004 Los Desafíos de la Interculturalidad. Identidad, Política y Derecho. Programa Internacional de Interculturalidad. Universidad de Chile, Santiago.

Champagne, P. y O. Christin

2004 Mouvements d'une Pensée. Pierre Bourdieu. Ed. Bordas, Paris.

Coronil, F.

2001 Toward a critique of globalcentrism: Speculations on capitalism's nature. En Millennial Capitalism and the Culture of Neoliberalism, editado por J. Comaroff y J. Comaroff, pp. 63-87. Duke University Press, Durham \& London.

Fassin, D.

1996 L'Espace Politique de la Santé: Essai de Généalogie. Presses Universitaires de France, Paris.

2000 Les Enjeux Politiques de la Santé. Editions Khartala, Paris.
2004 Le corps exposé. Essai d'économie morale de 1'illégitimité. En Le Gouvernement des Corps, coordinado por D. Fassin y D. Memmi, pp. 237-266. Editions de l'Ecole des Hautes Études en Sciences Sociales, Paris.

Fassin, D. y D. Memmi, coordinadores

2004 Le Gouvernement des Corps. Editions de l'École des Hautes Études en Sciences Sociales, Paris.

Fassin D. y D. Memmi

2004 Le gouvernement de la vie: Mode d'emploi. En Le Gouvernement des Corps, coordinado por D. Fassin y D. Memmi, pp. 9-33. Editions de l'École des Hautes Études en Sciences Sociales, Paris.

Ferguson, J. y A. Gupta

2002 Spatializing States: Toward an Ethnography of Neoliberal Governmentality. American Ethnologist 29(4):9811002.

Foerster, R. y J.I. Vergara

1996 ¿Relaciones interétnicas o relaciones fronterizas? Revista de Historia Indígena 1:9-33.

2000 Etnia y nación en la lucha por el reconocimiento. Los Mapuches en la sociedad chilena. Estudios Atacameños 19:11-42.

Foucault, M.

1994a La gouvernementalité. En Foucault. Dits et Écrits II, 1976-1988, pp. 635-657, Quarto Gallimard, Paris.

1994b Les mailles du pouvoir. En Foucault. Dits et Écrits II, 1976-1988, pp. 1001-1020, Quarto Gallimard, Paris.

Gobierno de Chile

2003 Unidad de Salud y Pueblos Indígenas. Ministerio de Salud, Santiago.

Goldman, M.

2005 Imperial Nature. The World Bank and Struggles for Social Justice in the Age of Globalization. Yale University Press, New Haven.

Gundermann, $\mathrm{H}$.

2003 Las poblaciones indígenas andinas de Chile y la experiencia de la ciudadanía. En Mapuches y Aymaras. El Debate en Torno al Reconocimiento y los Derechos Ciudadanos, editado por H. Gundermann, R. Foerster y J.I. Vergara, pp. 19-104, RIL Editores, PREDES/Universidad de Chile, Santiago.

Hale, C.R.

2002 Does multiculturalism menace? Governance, cultural rights and the politics of identity in Guatemala. Journal of Latin American Studies 34:485-524.

2004 Rethinking Indigenous Politics in the Era of the "Indio Permitido". NACLA Report on the Americas 38-2 (http://www.nacla.org/).

Hale, C.R. y R. Millaman

2005 Cultural agency and political struggle in the era of the 'indio permitido'. En Cultural Agency in the Americas, editado por D. Sommer, pp. 281-304. Duke University Press, Durham \& London.

Hill, J.D.

2002 Redelineando el curso de la historia: Estados EuroAmericanos y las Culturas sin Pueblos. En Colonización, Resistencia y Mestizaje en las Américas, editado por G. Boccara, pp. 13-26. Abya-Yala/ Instituto Francés de Estudios Andinos, Quito/Lima. 
Ibacache, J.

1999 Modelo de Salud Intercultural del Hospital Makewe. Tercer Encuentro de Salud y Pueblos Indígenas, Villarri$c a$, pp. 40-44. Ministerio de Salud, Santiago.

Jelves, I., M. Castro, J. Neira y J. Ibacache 2003 Kuyfike Kumeltun Zungu. Programa de Salud con Población Mapuche, 1992-2002. Servicio de Salud Araucanía Sur, mimeografiado, Temuco.

Kellner, R.

1993 The Mapuche during the Pinochet Dictatorship. Doctoral Dissertation, Clara Hall, University of Cambridge, Cambridge.

Kliksberg, B.

1999 Social capital and culture: Master keys to development. CEPAL Review 69:83-102.

Ministerio de Salud

2003 Política de Salud y Pueblos Indígenas. Gobierno de Chile, Santiago.

Nederveen Pieterse, J.

2001 Development Theory. Deconstructions/Reconstructions. Sage Publications, London.

Ong, A.

2002 Globalization and new strategies of ruling in developing countries. Études Rurales 163-164:233-248.

Orígenes

2004 Construyendo Juntos un Nuevo Camino (fascículo), Santiago.
Povinelli, E.

2002 The Cunning of Recognition: Indigenous Alterities and the Making of Australian Multiculturalism. Duke University Press, Durham \& London.

Radl, A.

2000 La Dimensión Cultural, Base para el Desarrollo de América Latina y el Caribe: Desde la Solidaridad Hacia la Integración. Banco Interamericano de Desarrollo, Documento de Divulgación 6, Washington DC.

Revel, J.

2005 Experiences de la Pensée. Michel Foucault. Editions Bordas, Paris.

Schild, V.

2000 Neo-liberalism's new gendered market citizens: The 'Civilizing' dimension of social programmes in Chile. Citizenship Studies 4(3):275-305.

Servicio de Salud Araucanía Sur

2002 Resultado de Estudio de Detección de Necesidades de Capacitación. Servicio de Salud Araucanía Sur/Programa Integral de Desarrollo con Comunidades Indígenas, Subcomponente Capacitación, Temuco.

Sivaramakrishnan, K. y A. Agrawal, editores

2003 Regional Modernities: The Cultural Politics of Development in India. Stanford University Press, Durham \& London.

Notas

1 El contrato de préstamo entre la República de Chile y el BID fue firmado en marzo del año 2001. El préstamo del BID es de US\$ 80 millones. El ejecutor principal del Estado de Chile es el MIDEPLAN (Ministerio de Planificación). El Componente Salud contó, en su primera fase, de un presupuesto de US\$ 6,7 millones.

2 Patrick Champagne y Olivier Christin (2004:221-222) dan la definición siguiente del concepto de campo social según Pierre Bourdieu: "Los campos son microcosmos más o menos autónomos que se ubican en el interior del macrocosmos social. Resultan del proceso de diferenciación social creciente que caracteriza a las sociedades modernas. Son universos sociales que se constituyen con sus propias referencias, su historia específica, su modo de reclutamiento, sus enjeux o apuestas particulares y su capital específico". Añaden además que "la noción de campo nos hace recordar que la realidad social es relacional y que lo que existe son relaciones objetivas entre posiciones sociales". En el caso que nos interesa aquí, hablamos de la salud intercultural como subcampo en la medida en que la elaboración de nuevos códigos simbólicos entre los agentes de este subcampo -facilitadores, terapeutas tradicionales, funcionarios de los distintos programas de salud intercultural, empleados de consultoras y ONGs, etc.- conduce a producir un espacio que tiende a la autonomización relativa y a la especialización. Como cualquier otro campo social, a medida que se desarrolla y se constituye, este universo simbólico forma sus instituciones, sus organizaciones, sus modos de ejercer influencia sobre los individuos, y conquista una autonomía que le permite, a su vez, estructurar las relaciones sociales (Bon- nevitz 2006:79). Ahora bien, conviene precisar que el subcampo de la salud intercultural no es del todo autónomo. En primer lugar, porque está englobado dentro del campo burocrático de la salud (MINSAL) y cada vez más dentro del campo burocrático político (MIDEPLAN). En segundo lugar, porque existe una homología entre la estructura social y este subcampo en la medida en que se encuentra atravesado por divisiones idénticas a las que oponen los distintos grupos sociales en la estructura del espacio social global. Por ejemplo, el médico no-indígena fuertemente dotado en capital económico y cultural tiende a ocupar una posición dominante dentro del espacio de la interculturalidad a pesar de que algunos funcionarios (enfermeras, auxiliares paramédicos, facilitadores) menos dotados en las distintas especies de capital tengan un mejor conocimiento de las prácticas terapéuticas y de las culturas indígenas. Del mismo modo, los llamados terapeutas tradicionales siguen ocupando, en tanto que indígenas pobres, las posiciones de dominados en el campo de la salud intercultural, a pesar de que son las personas que mayores conocimientos poseen con respecto del proceso salud-enfermedad en su sociedad.

3 En su analítica del poder, el filósofo francés Michel Foucault propuso salirse de las teorías de la soberanía para enfocarse sobre el gobierno de los individuos bajo la forma de la disciplina y del gobierno de las poblaciones bajo la forma del control del cuerpo social. En su texto clásico sobre el concepto de gubernamentalidad escribe lo siguiente: "Par gouvernementalité, j'entends l'ensemble constitué par les institutions, les procédures, analyses et réflexions, les calculs et les tactiques qui permettent 
d'exercer cette forme bien spécifique, bien que complexe, de pouvoir, qui a pour cible principale la population, pour forme majeure de savoir, l'économie politique, pour instrument technique essentiel les dispositifs de sécurité. Deuxièmement, par 'gouvernementalité' j' entends la tendance, la ligne de force qui, dans tout l' Occident, n'a pas cessé de conduire (...) vers la prééminence de ce type de pouvoir qu'on peut appeler le 'gouvernement' sur tous les autres: souveraineté, discipline (...)" (Foucault 1994a:655). Sobre la distinción entre anatomopolítica y biopolítica que explicitamos más adelante véase la conferencia de Foucault titulada Les mailles du pouvoir (Foucault 1994b). Para una excelente síntesis con respecto de la concepción foucaultiana del poder véase el libro de la filósofa francesa Judith Revel (2005).

4 Definimos al Estado neoliberal diferencialista como un Estado que funciona en base a una nueva gestión de la diferencia cultural y que tiende a responsabilizar a los agentes sociales definidos en función de características casi naturales. Una corriente interpretativa reciente (Agrawal 2005; Ferguson y Gupta 2002; Goldman 2005; Hale 2002; Ong 2002) plantea que las prácticas de Estado en cuanto a la gestión del espacio y de la población nacional han experimentado transformaciones notables en las dos últimas décadas. Fuertemente influenciados por las conceptualizaciones foucaultianas del poder en sus dimensiones productivas (incitar, producir individualidades funcionales, etc.) más que negativas (reprimir, censurar, etc.), estos autores afirman que las modalidades de gobierno en la era global pueden entenderse bajo el rótulo de gubernamentalidad. En otros términos, el Estado se interesa por la conducta de las conductas de la población. Añaden, además, que esta gubernamentalidad opera de manera diferenciada, segmentando el cuerpo social en una infinidad de grupos y subjetividades o seccionando lo social en una multitud de microespacios definidos en función del género, del origen étnico, del grado de exclusión social, etc. (Schild 2000). Es así como para varios estudiosos, el multiculturalismo puede ser interpretado como una modalidad de este nuevo arte de gobierno en tiempos de globalización (Hale 2002; Povinelli 2002). La gubernamentalización de la cultura a través de nuevos procedimientos de encuesta, demarcación, protección, fortalecimiento y "marketeo" de lo étnico contribuye a transformar el paisaje institucional y conduce a la gente a reformular el entendimiento del hecho cultural. Las localidades indígenas gubernamentalizadas y las nuevas comunidades regulatorias (agencias o programas de Estado, asociaciones, mesas de diálogo, etc.) son parte de un nuevo régimen de control que tiende a crear nuevas relaciones político-económicas entre los centros, las localidades y los sujetos étnicos, los cuales se encuentran atados por el hilo de poder del Estado.

5 En un documento del Ministerio de Salud publicado en 2003, el propósito de la Política de Salud con Pueblos Indígenas se encuentra definido de la manera siguiente: "Contribuir al mejoramiento de la situación de salud de la población indígena, a través del desarrollo progresivo de un modelo de salud con enfoque intercultural, que involucre la activa participación de los pueblos originarios en su construcción; y apoyar la formulación, financiamien- to e implementación de programas, estrategias y actividades, que aporten a la disminución de las brechas sanitarias en materia de acceso, calidad y efectividad" (Ministerio de Salud 2003:21).

6 En este aspecto, los planteamientos de Orígenes representan un retroceso con respecto de las recientes conceptualizaciones de la Unidad de Salud con Pueblos Indígenas del MINSAL. En efecto, en un documento de trabajo interno de 2003, se menciona el aspecto siguiente con respecto de la implementación de un modelo de salud intercultural: "Un requisito fundamental para el desarrollo de un modelo intercultural en salud es el reconocimiento de la existencia de modelos médicos tanto 'formales' (oficiales) como 'informales' (tradicionales) interconectados entre sí en la práctica. Esta interconexión no está dada necesariamente por los sistemas de referencia y contrarreferencia convencionales, sino por la elección y preferencia de las personas y el acceso real que la población tiene a cada uno de ellos. En las experiencias de modelo de atención de salud intercultural existentes, la complementariedad entre sistemas médicos es intencionada y promovida y la articulación entre ambos permite al aprovechamiento de los recursos de salud oficiales y comunitarios disponibles" (Gobierno de Chile 2003:7). A través de esta formulación, los profesionales de la Unidad de Salud con Población Indígena del MINSAL evitan esencializar y purificar las prácticas y el sistema de representaciones referente a la salud de los usuarios indígenas. Por otra parte reconocen que además de remitir a una política de Estado, la interculturalidad ya está presente entre los usuarios que recurren a distintos sistemas médicos en la búsqueda de una solución integral a sus problemas de salud. Sobre el tema del carácter "mezclado" de las prácticas y representaciones en salud de los Mapuche véase Boccara (2000), Boccara et al. (1999) e Ibacache (1999).

7 Véase, entre otros, los trabajos de Kliksberg (1999) y Radl (2000). Para una crítica de este enfoque que pone el énfasis sobre la cultura como determinante de los problemas sociales, políticos, económicos, etc. véase, entre otros, los estudios de Hale $(2002,2004)$ y Nederveen Pieterse (2001).

8 Unidad de Salud con Población Mapuche del Servicio de Salud Araucanía Sur.

9 Hospital rural dirigido desde marzo del año 1999 por una asociación mapuche. Representa una de las primeras experiencias en salud complementaria comunitaria.

10 Entrevista realizada por el autor el día 16 de enero del año 2004 en la ciudad de Temuco (Chile, IX Región).

11 El poco entusiasmo de los médicos ya se encuentra mencionado en el Estudio de detección de necesidades de capacitación realizado en 2002 (Servicio de Salud Araucanía Sur).

12 En la última década, varios estudiosos han insistido sobre las determinaciones recíprocas entre los procesos de resistencia política y las transformaciones culturales e identitarias de las sociedades amerindias. Se ha planteado la hipótesis según la cual las sociedades indígenas de América Latina se destacan por su capacidad a incorporar la alteridad. Se llegó a afirmar que lo que caracterizaba a estas sociedades en la época colonial y lo que las sigue caracterizando durante el período republicano, es 
una lógica mestizaje. Para una presentación sintética de estos planteamientos véase los volúmenes editados por el autor (Boccara 2000, 2002).

13 La dicotomía entre tradición y modernidad es fluctuante. Es una construcción social que debe ser abordada desde una perspectiva relacional. No es posible pensar la llamada medicina tradicional sin la biomedicina, tanto desde el punto de vista de las prácticas de los enfermos como desde la perspectiva de la construcción del saber y de las relaciones de poder entre agentes de salud legítimos e ilegítimos. La línea entre las distintas prácticas y representaciones fluctúa en función de las configuraciones de poder y del Estado del saber. No es sólo que en la práctica los enfermos usan los distintos tipos de medicina sucesiva o simultáneamente, sino que además modernidad y tradición son construcciones ideológicas que sirven de argumentos en los debates de sociedad y cuyo límite refleja el Estado de las relaciones de fuerza en un momento dado de la historia (Fassin 2000:96). De hecho, las prácticas terapéuticas mapuche otrora demonizadas fueron luego ridiculizadas o percibidas como simples supersticiones para transformarse recientemente en saber médico digno de respecto.

14 La entrevista tuvo lugar el día 14 de enero del año 2004 en la ciudad de Temuco (Chile, IX Región). Hago uso aquí de un pseudónimo para mantener el anonimato de la entrevistada.

15 Para una crítica a la corriente historiográfica de los Estudios Fronterizos que plantean la idea según la cual los mapuche habrían sido incorporados al Estado-nación de manera pacífica véase Boccara (1999) y Foerster y Vergara (1996).

16 Autor: ¿Cuál fue el objetivo de los talleres? Ingrid Quintana: Tienen que entender [los funcionarios de la salud] que como mapuche tengo una visión del mundo. Pusimos a José Quidel porque es investigador, es profesor, es otro más de ellos. Es como poner a un médico mapuche entre los médicos wingka. Entonces esto implica trabajar con las mismas armas que ellos dicen que hay que tener para validar el conocimiento. Además José no se enojaba. Era pedagogo. Se esforzaba mucho para que la gente entendiera pero sin traicionar o simplificar el pensamiento y el conocimiento mapuche a través del uso de traducciones baratas.

17 Ingrid Quintana me señaló lo siguiente: Un tema que siempre volvía era que ya no hay más Mapuche (en Perquenco, en Currarehue) [...]. En un taller, una mujer se presentó como mapuche en mapudungun. La gente quedó sorprendida. Eso sirvió para mostrar que había mapuche, que los mapuche ¡mira que saben!, y además ¡están entre ustedes!

18 Para un análisis sociohistórico detallado de la genealogía de la salud pública y de las diferencias entre salud tradicional y génesis del espacio político de la salud pública véase el trabajo de Didier Fassin (1996).

19 Cabe recordar dos cosas al respecto. En primer lugar, antes de que el censo poblacional de 1993 arrojara la cifra de 1 millón de mapuche viviendo en territorio chileno, la mayoría de la gente (los agentes de Estado incluidos) es- taba convencida de que quedaban muy poco mapuche en Chile. Los mapuche representaban un grupo residual en proceso acelerado de disolución o asimilación y era tan invisible socialmente como inexistente estadísticamente. En segundo lugar, cuando, a principios de los años 1990, las movilizaciones mapuche se intensificaron y las reivindicaciones indígenas cambiaron de naturaleza, el aparato de Estado tardó en reaccionar ya que no disponía de las herramientas para leer y por consiguiente canalizar este nuevo movimiento social. Los agentes de Estado no entendían lo que estaba pasando, no sabían quiénes se estaban organizando, como tampoco captaban la lógica política indígena que se desarrollaba fuera del ámbito tradicional de los partidos políticos y de los sindicatos. Sobrepasado por la efervescencia del movimiento social mapuche, el Estado chileno organizó primero la represión y después la llamada participación a través de los diálogos comunales (1999) y de la implementación del Programa Orígenes (2001). Se puede decir que en poco más de una década, gracias a la asesoría internacional, a la cooptación de parte de la intelectualidad mapuche, a la cooperación de numerosos científicos sociales y al encarcelamiento de varios líderes políticos indígenas, el Estado multicultural y neoliberal ha recuperado el tiempo y el espacio perdido. Sobre los temas de la emergencia de un Estado multicultural, de la codificación de las luchas sociales en términos étnicos y de la idea de ciudadanía cultural en el norte de Chile véase el trabajo de Gundermann (2003). Finalmente, para un análisis teórico de la noción de multiculturalismo informado por un trabajo de recolección de datos empíricos sobre la política del gobierno chileno con respecto de los pueblos indígenas durante la última década véase Foerster y Vergara (2000).

20 En un texto que trata de las innovaciones en las tecnologías políticas ocurridas entre los siglos XVII y XVIII, Michel Foucault (1994b) distingue entre las técnicas de la individualización del poder o la disciplina, cuyo objetivo es el individuo en su cuerpo, y su comportamiento, y otro grupo de tecnologías de poder que se dirigen hacia la población. Las primeras tecnologías son definidas por Foucault bajo el término de anatomopolítica y las segundas como biopolítica. La centralidad de los programas de salud intercultural en la implementación del multiculturalismo de Estado así como la multiplicación de las encuestas relativas a la población indígena (censos diversos, medición de las tasas de mortalidad, fertilidad, etc.) en los últimos años permiten hacer la hipótesis según la cual el neoindigenismo de Estado en la América Latina del tercer milenio estaría tomando la forma de un biopoder, después de haberse ejercitado durante gran parte del siglo XX esencialmente bajo la forma de la disciplina. Para un análisis en términos foucaultiano del ejercicio de un biopoder en el campo de la salud véase el trabajo pionero de Didier Fassin (2000).

21 El hecho de incitar a que los sujetos se gobiernen ellos mismos no implica por supuesto la desaparición de la sanción en contra de los despistados o déviants que se atreven a poner en tela de juicio al nuevo pacto social establecido alrededor de la nueva norma o normativa (Fassin 2004). 